REVISED

\title{
Rapid evaporation at the superheat limit of methanol, ethanol, butanol and n-heptane on platinum films supported by low-stress SiN membranes
}

\author{
Eric J. Ching ${ }^{1}$, C. Thomas Avedisian ${ }^{1 *}$, Richard C. Cavicchi ${ }^{2}$, \\ Do Hyun Chung ${ }^{1}$, Jeff Rah ${ }^{1}$, Michael J. Carrier ${ }^{2}$ \\ ${ }^{1}$ Sibley School of Mechanical and Aerospace Engineering \\ Cornell University, Ithaca, NY 14853, USA \\ ${ }^{2}$ Biomolecular Measurement Division \\ National Institute of Standards and Technology, Gaithersburg, MD 20899, USA
}

\begin{abstract}
The bubble nucleation temperatures of several organic liquids (methanol, ethanol, butanol, n-heptane) on stress-minimized platinum (Pt) films supported by $\mathrm{SiN}$ membranes is examined by pulse-heating the membranes for times ranging from $1 \mu \mathrm{s}$ to $10 \mu \mathrm{s}$. The results show that the nucleation temperatures increase as the heating rates of the Pt films increase. Measured nucleation temperatures approach predicted superheat limits for the smallest pulse times which correspond to heating rates over $10^{8} \mathrm{~K} / \mathrm{s}$, while nucleation temperatures are significantly lower for the longest pulse times. The microheater membranes were found to be robust for millions of pulse cycles, which suggests their potential in applications for moving fluids on the microscale and for more fundamental studies of phase transitions of metastable liquids.
\end{abstract}

KEY WORDS: Homogeneous nucleation, Boiling, Superheat limit, Bubble nucleation, Bubbles, Pulse heating

*author of correspondence; cta2@ cornell.edu 


\section{Introduction}

Most liquid-to-vapor phase transitions are triggered at a few degrees of superheat owing to gases trapped in surface imperfections ${ }^{1}$. In certain applications the liquid can be heated well above its normal boiling point even when in contact with a solid. This situation arises when bubbles nucleated from solid imperfections do not grow and detach from the surface fast enough to prevent initiation of a phase transition by random density fluctuations that form bubbles in metastable equilibrium with the liquid - the process of homogeneous nucleation.

Homogeneous nucleation is relevant to a number of applications including laser heating of polymer particles with encapsulated drugs [1], explosive boiling during combustion of fuel droplets [2], thermal inkjet concepts for printing [3-6], flash vaporization of fuel injected into combustion engines [7], and formation of films of quantum dot composites to fabricate color AC-driven displays [8]. A variety of configurations have been employed to measure the thermal state that triggers a phase change by homogeneous nucleation, including heating liquids by micrometer diameter wires or within sealed glass tubes, and slowly heating volatile liquid droplets in heavier immiscible host fluids [9].

In applications that involve high frequency thermal cycling and bubble formation (e.g., ink jet printing), sustained operation is determined by the durability of the device. Solid state platforms that employ metal films supported by solid substrates have successfully been used to study a variety of aspects related to bubble nucleation of superheated water, including microbubble morphology and the effects of heating rate on the volumetrically averaged film temperature [4-6,10-14]. More recently, a Pt film supported by a membrane with air on the backside was used to examine bubble nucleation of water [15]. The results showed that such

\footnotetext{
${ }^{1}$ The term "superheat" is defined as the difference between a liquid's temperature above its boiling point and its boiling point at the prevailing pressure. The "superheat limit" is the liquid temperature associated with a phase transition initiated by random density fluctuations that produce bubbles in metastable equilibrium with the surrounding liquid. Such a process may occur in the bulk of a liquid or at a microscopically smooth solid surface in contact with the liquid.
} 
structures more efficiently heat the fluid by reducing backside thermal losses by the lower thermal effusivity vapor in contact with the membrane. Less power was found to nucleate bubbles compared to substrate-supported thin films. Figure 1 is a schematic of the design of the structures employed showing the heat flows involved.

It can be more problematic to measure the superheat limit of organic fluids because they have properties less favorable for detecting bubble nucleation compared to water, as discussed in Section 2, when information about bubble nucleation relies exclusively on the evolution of surface temperature during heating. In this paper, we examine the efficacy of pulse-heating Pt films supported by SiN membrane structures to promote bubble nucleation of several alcohols and a normal alkane as representative organics using pulse times that give heating rates approaching $10^{9} \mathrm{~K} / \mathrm{s}$. The fluids selected for study are methanol, ethanol, butanol and heptane as representative of a range of organic liquids. The measurement principle for temperature is discussed in the next section followed by an outline of the experimental method. Results are then presented along with some supporting analysis.

\section{Measurement Principle}

A metal film immersed in a pool of the test liquid is heated by an electrical current passing through the film (e.g., $\mathrm{q}_{\text {in }}$, figure 1) and its temperature is monitored during the heating process. The expected form of the evolution of the volumetrically averaged film temperature is schematically shown in figure 2. Prior to nucleation, heat will be dissipated in the liquid and the temperature will increase in a somewhat exponential manner in keeping with the low thermal mass of the membrane films. After nucleation and the bubbles grow to cover the surface, its temperature will increase at a rate dictated by vapor properties. The difference between liquid and vapor properties determines the extent to which the nucleation process can be revealed by measuring the evolution of temperature during the heating process. 
While maintaining $\mathrm{q}_{\text {in }}$, the heating rate will change as the liquid at the surface is removed and replaced by vapor due to the bubble growth process.

The temperature corresponding to the inflection point in figure $2,\left.\frac{\partial^{2} \mathrm{~T}}{\partial \mathrm{t}^{2}}\right|_{\mathrm{t}=\mathrm{t}^{*}}=0$ (symbols are defined in the "nomenclature" section), is taken as the nucleation temperature ( $\left.\mathrm{T}_{\text {nuc }}\right)$. The actual nucleation event, however - and especially if it occurs by density fluctuations in the liquid - will occur on length scales too small (order of angstroms owing to the high saturation pressures typical of evaporation at the superheat limit) to initially affect surface temperature. The nucleated bubble must grow to cover a large enough fraction of the surface to influence heat transfer $\left(\mathrm{q}_{\mathrm{F}}\right.$ in figure 1) for a phase transition to be detected using this mathematical criterion. Both the bubble growth time and heating rate for energy transport in the liquid and vapor determine the extent to which the evolution of temperature will be sensitive enough to fluid property changes (the transition of liquid-to-vapor contact of the surface with the fluid) to yield a detectable inflection point.

The bubble growth time, $t_{b}$, is modeled as the time for a bubble to grow to the characteristic dimension $\left(\mathrm{L}_{\mathrm{c}}\right)$ of the metal film. For bubble growth at a surface it can be shown that [16] $\mathrm{t}_{\mathrm{b}} \approx \frac{\mathrm{L}_{\mathrm{c}}^{2}}{\alpha \mathrm{Ja}^{2}}$. When normalized by the thermal diffusion time, $\mathrm{L}_{\mathrm{c}}^{2} / \alpha$, we can write that $\Delta \tau^{*} \equiv \mathrm{t}_{\mathrm{b}} /\left(\mathrm{L}_{\mathrm{c}}^{2} / \alpha\right)=1 / \mathrm{Ja}^{2}$ where $\mathrm{Ja} \equiv \frac{\left(\mathrm{T}_{\mathrm{w}}-\mathrm{T}_{\mathrm{b}}\right) \mathrm{c}_{\mathrm{pL}} \rho_{\mathrm{L}}}{\mathrm{h}_{\mathrm{fg}} \rho_{\mathrm{v}}}$. For the temperature gradient in the fluid at the surface, a one-dimensional semi-infinite solid model is used with a heat flux imposed at the interface between the solid $(\mathrm{Pt})$ and fluid. The solution to this problem [17] can be put in a form that expresses the ratio of heating rates in terms of thermal effusivities as $\left.\frac{\partial \mathrm{T}}{\partial \mathrm{t}}\right|_{\mathrm{v}} /\left.\frac{\partial \mathrm{T}}{\partial \mathrm{t}}\right|_{\mathrm{L}} \equiv \xi \approx \frac{\gamma_{\mathrm{L}}}{\gamma_{\mathrm{V}}}$. 
Using water ("w") as a reference and representative property values of the fluids investigated in this study [18-20], we find that $8<\Delta \mathrm{t} * / \Delta \mathrm{t}^{*}{ }_{\mathrm{w}}<13$ and $0.1<\xi / \xi_{\mathrm{w}}<0.32$. On this basis, it should be rather more difficult to detect differences in heating rates across the inflection point for the organic fluids compared to water. However, the metrology described in Section 3 is nonetheless shown to have sufficient resolution to enable accurate measurement of the nucleation temperature.

\section{Experiment}

The principle for measuring temperature is based on monitoring the electrical resistance of the metal film during an input electrical power pulse, and then converting the measured resistance to temperature with the aid of a separate calibration of resistance with temperature. The approach described in [15] is used here.

The heater configurations are shown in the photomicrograph of figure 3a. A crosssectional schematic is shown in figure 3b. Details of the fabrication process are discussed in [21]. A silicon substrate was coated by a $200 \mathrm{~nm}$ thick SiN layer followed by patterning a Ti adhesion layer and then a platinum (Pt) film. A membrane was created by etching the Si to completely remove the exposed area giving the configuration shown in the top view of figure $3 \mathrm{a}$ and the cross-sectional schematic in figure $3 \mathrm{~b}$. The region $\mathrm{L}_{1} \times \mathrm{L}_{2}$ in figure $3 \mathrm{a}$ is the active area for nucleation. Two lengths $\left(\mathrm{L}_{1}\right)$ were employed $(60 \mu \mathrm{m}$ and $80 \mu \mathrm{m})$ while $\mathrm{L}_{2}$ was fixed at $4 \mu \mathrm{m}$ giving aspect ratios $\left(\mathrm{L}_{1} / \mathrm{L}_{2}\right)$ of 15 and 20 , respectively. No differences were found in the reported results for these two aspect ratios. The thickness of the metal film was fixed at $200 \mathrm{~nm}$. To facilitate measuring electrical resistance during a power pulse, chips with patterned microheaters were glued in the recesses of 40-pin dual-in-line packages (DIPs, figure 3c). A $1.5 \mathrm{~mm}$ hole was drilled in the center of the DIP to allow the back side of the chip to be in direct contact with air. 
The DIPs were incorporated into one leg of a bridge circuit. Figure $4 \mathrm{a}$ is a schematic of the circuit and figure $4 \mathrm{~b}$ is a photograph of the component layout. The bridge allowed for measurement of the change of output voltages $\left(\mathrm{V}_{\text {out }}\right)$ corresponding to input voltages $\left(\mathrm{V}_{\text {in }}\right)$ of varying pulse widths $(\tau)$. The DIPs were mounted in sockets soldered to the printed circuit board to provide for their easy removal. Electrical connections from two pins of active microheaters to the bridge were facilitated by providing jumper connections on the DIP.

An artefact of short duration voltage pulses is the appearance of spikes in the evolution of $\mathrm{V}_{\text {out }}$ at the beginning and end of a pulse. Capacitance and inductive filtering of the bridge was employed to minimize the influence of these spikes. Of particular importance was the need for inductive filtering ( $\mathrm{L}$ in figure $4 \mathrm{a}$ ). A hand-wound copper coil was previously employed [15] to adjust bridge inductance by manually compressing or expanding the coil as necessary. It provided for rather imprecise control of noise. For the present study a variable solid state inductor (\#TK2820-ND (Toko America, Inc. ${ }^{2}$ )) is used that facilitates tuning out high frequency noise at the beginning and end of a pulse. With this component, the control of inductance was found to be more precise.

The average heater temperature, $\mathrm{T}(\mathrm{t})$, is inferred from the electrical resistance of the membrane and standard equations that relate $R_{h}$ to $V_{\text {out }}$ and the other parameters in figure $4 a$. A calibration process converts $\mathrm{R}_{\mathrm{h}}$ to temperature. Fig. 5 shows a typical calibration result for three thermal cycles corresponding to a microheater with dimensions (figure $3 \mathrm{a}$ ) $\mathrm{L}_{1}=60 \mu \mathrm{m}$ and $\mathrm{L}_{2}=4 \mu \mathrm{m}$. The variation of total electrical resistance with temperature is shown over the range $320^{\circ} \mathrm{K}$ to $650^{\circ} \mathrm{K}$ for an oven heating rate of $1^{\circ} \mathrm{K} / \mathrm{min}$. Multiple cycles were required to stabilize the metal films (e.g., three cycles are shown in figure 5). For the $(4 \mu \mathrm{m} \times 60 \mu \mathrm{m})$ microheater the calibration process gave $\theta \approx 0.00271^{\circ} \mathrm{K}^{-1}$ while for the $(4 \mu \mathrm{m} \times 80 \mu \mathrm{m})$

\footnotetext{
${ }^{2}$ Certain commercial equipment or materials are identified in this paper in order to specify adequately the experimental procedures. Such identification does not imply recommendation or endorsement by the National Institute of Standards and Technology, nor does it imply that the materials or equipment identified are necessarily the best available for the purpose.
} 
microheater $\theta \approx 0.002197^{\circ} \mathrm{K}^{-1}$. These values were used to convert resistance to temperature in eq. 1 .

In view of the results in figure 5 a linear relationship of the form

$$
\mathrm{T}(\mathrm{t})=\frac{1}{\theta}\left(\frac{\mathrm{R}_{\mathrm{h}}(\mathrm{t})}{\mathrm{R}_{\mathrm{ho}}}-1\right)+\mathrm{T}_{\mathrm{o}}
$$

was developed to correlate the data in figure 5 where $\theta$ is the temperature coefficient of resistance (TCR). The temperature in eq. 1 is a volumetrically averaged value because of the ostensibly uniform internal energy generation within the metal film by the current flowing in it during a power pulse.

A thermal pulsing operation was initiated by first flooding a chip with the test liquid. The liquids were confined to the chip with a cuvette glued to the DIP (not shown in figure 3) because of their propensity to wet Pt. A pulse generator (Agilent \# 8411A pulse generator) delivered square voltage pulses $\left(\mathrm{V}_{\text {in }}(\mathrm{t})\right)$ to the bridge at prescribed $\tau$ values of $1 \mu \mathrm{s}, 2 \mu \mathrm{s}, 3 \mu \mathrm{s}$, $5 \mu \mathrm{s}$, and $10 \mu \mathrm{s}$. Longer pulse times tended to promote a cyclic bubble growth/collapse cycle [12] that made it difficult to reach temperatures near to the superheat limit. It is noted that the membrane Pt films remained intact over millions of pulse heating operations, only suffering damage when the input voltage is inadvertently set too high, or the pulse time set too low that makes it difficult to position the inflection point at the desired time, both of which could result in the post-nucleation temperatures exceeding the melting point. The measured output voltages, $\mathrm{V}_{\text {out }}(\mathrm{t})$, were stored in a digital oscilloscope (LeCroy Waverunner 44xi 5Gs/s) and transported to a PC for subsequent processing.

The bridge design of figure 4 provides $\mathrm{V}_{\text {out }}$ data by a two-point method. It is necessary to correct for the effect of lead wires and other resistors in the network to access the desired resistance over the $\mathrm{L}_{1} \times \mathrm{L}_{2} \times \delta$ volume in figure 3 . The conversion of $\mathrm{V}_{\text {out }}$ to $\mathrm{R}_{\mathrm{h}}$ and 
$\mathrm{T}$ is carried out as described in [15], and will not be elaborated upon here. A standard bridge equation

$$
\mathrm{R}_{\mathrm{mp}}(\mathrm{t})=\mathrm{R}_{\mathrm{p}} \frac{1-\frac{\mathrm{V}_{\text {out }}(\mathrm{t})}{\mathrm{V}_{\text {in }}}\left(\frac{\mathrm{R}_{\mathrm{p}}+\mathrm{R}_{\text {jumper }}+\mathrm{R}_{1}}{\mathrm{R}_{\mathrm{p}}+\mathrm{R}_{\text {jumper }}}\right)}{1+\frac{\mathrm{V}_{\text {out }}(\mathrm{t})}{\mathrm{V}_{\text {in }}}\left(\frac{\mathrm{R}_{\mathrm{p}}+\mathrm{R}_{\text {jumper }}+\mathrm{R}_{1}}{\mathrm{R}_{1}}\right)}
$$

is used to relate the measured output voltage, $\mathrm{V}_{\text {out }}$, to the total resistance which includes all of the connecting wires. $R_{p}$ is tunable during the bridge balancing operations and $R_{\text {jumper }}$ is selectable over three values indicated in figure $4 a$ (i.e., $R_{2,3,4}$ ). $R_{5}$ represents lead resistance. The resistance values are listed in Table 1 of [15]. The time-dependence of $R_{m p}$ in eq. 2 is carried entirely in $\mathrm{V}_{\text {out }}$ because the other resistances are stable against temperature. With $R_{m p}$ known the resistance of the Pt metallization, $R_{h}$, is obtained from

$$
\mathrm{R}_{\mathrm{h}}(\mathrm{t})=\mathrm{R}_{\mathrm{ho}}+\left(\mathrm{R}_{\mathrm{mp}}(\mathrm{t})-\mathrm{R}_{\mathrm{mpo}}\right)
$$

whereby Eq. 1 is then used to determine the temperature. Appendix A discusses the uncertainty of measured temperatures.

\section{Results and Discussion}

Experimental measurements for the four fluids examined are given in figures 6-9 corresponding for the indicated $V_{\text {in }}(t)$ and $\tau$. For each $\tau, V_{\text {in }}$ was adjusted so that the time $\left(t^{*}\right)$ at which nucleation occurred corresponded to approximately $0.8 \tau$ as a matter of convenience. The data are averages of 500 pulses for the given fluid. For each pulse time shown the evolution of temperature includes the slope at $t^{*}$ which marks the occurrence of bubble nucleation. The heating rates at $t^{*}$ are also shown in figures 6-9. The bubble nucleation event was quite distinct for all fluids and pulse times as shown in figures 6-9.

From the data in figures 6-9, the nucleation temperatures $\left(\mathrm{T}_{\text {nuc }}\right)$ were obtained by spline-fitting the temperatures using the procedure of Lundgren [22]. The values are listed in 
Tables 1-4. As noted in Appendix A, the uncertainty in the reported temperatures resulting is estimated to be less than one degree. Figure 10 shows the variation of reduced nucleation temperature $\left(\mathrm{T}_{\text {nud }} / \mathrm{T}_{\mathrm{c}}\right)$ with heating rate. The curves are included to enhance the trend.

The reduced temperatures increase with increasing heating rates (or reducing pulse times) as shown in figure 10. At the lowest heating rates (longest pulse times), $\mathrm{T}_{\mathrm{nud}} / \mathrm{T}_{\mathrm{c}} \sim 0.82$ 0.85 and increase to what appears to be a limiting range of $\mathrm{T}_{\mathrm{nud}} / \mathrm{T}_{\mathrm{c}} \sim 0.9$ to 0.92 , at the highest heating rates (shortest pulse times). These values provide clues of the possible mechanism responsible for bubble nucleation in the experiments.

Firstly, for nucleate boiling at close to the normal boiling point of a fluid reduced temperatures are typically in the range 0.65 to 0.71 (e.g., using values listed in Table 1). Even the smallest reduced temperatures measured in the present experiments are much higher, which would seem to rule out the role of trapped gases in surface imperfections as a mechanism to trigger a phase transition on the pulse heated structures employed in the experiments. Secondly, for the highest heating rates (shortest pulse times) the trends appear to saturate at in the range noted above (0.9 to 0.92). Data for a wide range of fluids $[9,23]$ show that reduced temperatures of approximately 0.9 at atmospheric pressure are typical of a homogeneous nucleation processes (based on classical nucleation theory).

The fact that the nucleation temperatures in figure 10 appear to saturate as heating rate increases (the corresponding temperatures are listed in the last column in Table 5) could be evidence that the upper limits correspond to the superheat limit of the fluids investigated, $\mathrm{T}_{\mathrm{SL}}$. To determine if this is the case, we use classical nucleation theory to predict $\mathrm{T}_{\mathrm{SL}}$. In this effort, no account is included of the subsequent growth of the bubble to macroscopic size. Rather, we predict only the initial conditions for such growth. Since the liquid is in contact with the metal membrane nucleation at a surface is considered. 
Nucleation theory relates the rate $\left(\mathrm{J}_{\mathrm{s}}\right)$ of forming bubbles in metastable equilibrium with the surrounding liquid per unit surface area ("metastable" because the addition or loss of molecules to an equilibrium bubble would theoretically result in its further growth or collapse, respectively) to the energy of forming such bubbles, $\Delta \Omega$, in a liquid maintained at constant temperature and pressure. Under such conditions $\Delta \Omega$ is equivalent to the increase of the availability of the system.

The superheat limit, $\mathrm{T}_{\mathrm{SL}}$, can be shown to be related to $\Delta \Omega$ and $\mathrm{J}_{\mathrm{S}}$ as

$$
\mathrm{T}_{\mathrm{SL}}=\frac{\Delta \Omega}{\mathrm{K}}\left[\ln \left(\frac{\mathrm{C}}{\mathrm{J}_{\mathrm{s}}}\right)\right]^{-1}
$$

where

$$
\Delta \Omega=\frac{16 \pi \sigma^{3}}{3\left(\mathrm{P}-\mathrm{P}_{\mathrm{o}}\right)^{2}}
$$

and the pressure in the bubble is related to the saturation pressure as

$$
\mathrm{P}=\mathrm{P}_{\mathrm{S}} \exp \left(\frac{\mathrm{v}_{\mathrm{L}}}{\mathrm{RT}_{\mathrm{SL}}}\left[\mathrm{P}_{\mathrm{S}}-\mathrm{P}_{\mathrm{O}}\right]^{2}\right)
$$

$\mathrm{C}$ is a kinetic factor that relates to the growth and decay of bubbles from evaporation and condensation of individual molecules at the interface between the vapor and surrounding liquid lattice [24,25],

$$
\mathrm{C}=\sqrt{\frac{2 \sigma}{\pi \mathrm{m}}} \mathrm{N}_{\mathrm{o}}
$$

The number density $\mathrm{N}_{\mathrm{o}}$ (molecules per unit surface area, $\mathrm{m}^{-2}$ ) is [26] $\mathrm{N}_{\mathrm{o}}=\left(\mathrm{mv}_{\mathrm{L}}\right)^{-2 / 3}$.

Eqs. 5 and 7 assume that the shape of the metastable bubble is spherical. Corrections due to contact angle (e.g., bubble shape as a truncated sphere) have been considered [26]. The corresponding superheat limits can be considerably lower than the spherical bubble assumption. Because the contact angle is not known under the thermal conditions of the 
experiments, the best that could be done is to use contact angle as a fitting parameter to match predicted and measured superheat limits. However, with the emphasis of the present study on applying the pulse heating experimental arrangement of figure 4 to organic liquids to determine the sensitivity of the metrology to detect nucleation of such systems, we assume the simplest shape of a spherical bubble (i.e., zero contact angle). The predicted $\mathrm{T}_{\mathrm{SL}}$ should be the highest.

The nucleation rate must be known to solve eq. 4 . Since consideration here is for nucleation at a surface, $\mathbf{J}_{\mathrm{s}}$ is approximated as $[5,9]$

$$
\mathrm{J}_{\mathrm{s}} \approx \frac{1}{\mathrm{~A}}\left|\frac{\mathrm{d}\left(\Delta \Omega /\left(\mathrm{KT}_{\mathrm{SL}}\right)\right)}{\mathrm{dT}_{\mathrm{SL}}}\right| \frac{\mathrm{dT}_{\mathrm{SL}}}{\mathrm{dt}}
$$

The derivative $\frac{\mathrm{d}\left(\Delta \Omega /\left(\mathrm{KT}_{\mathrm{SL}}\right)\right)}{\mathrm{dT}_{\mathrm{SL}}}$ is evaluated using correlations for $\mathrm{P}_{\mathrm{s}}$, $\mathrm{v}_{\mathrm{L}}$, and $\sigma$. Bulk properties were determined from published correlations as follows: for $\mathrm{P}_{\mathrm{s}}$ correlations in [27] were used for the alcohols and the formulation in [28] was used for n-heptane; for $\sigma$ the formulations presented in [29] were used for alcohols and the correlation in [30] for heptane; and $\mathrm{v}_{\mathrm{L}}$ was obtained using the recommendations in [31]. All of the correlations required significant extrapolations of the saturated state into the domain of metastable state, which will undoubtedly be a source of uncertainty.

From eq. 8, and using the highest measured heating rates for the shortest pulse widths of the experiments, we found that $\mathrm{J}_{\mathrm{s}} \approx 10^{21} / \mathrm{m}^{2}$-s for the fluids investigated. Because $\mathrm{J}_{\mathrm{s}}$ and $\mathrm{dT}_{\mathrm{SL}} / \mathrm{dt}$ appear in a logarithmic term in eq. $4 \mathrm{~T}_{\mathrm{SL}}$ is quite insensitive to variations in them over many orders of magnitude. The influence of heating rate will be stronger in the postnucleation bubble growth process (not considered in this study).

As is evident from figure 10, the highest nucleation temperatures are associated with the highest heating rates (and shortest pulse times). The limiting values ( $\mathrm{T}_{\text {nuc }}$ in Table 5) will 
be most relevant to compare with predictions. The last column of Table 5 lists the predicted $\mathrm{T}_{\mathrm{SL}}$ by solving eqs. 4-8 with property estimates as noted previously The results give some support for the measured temperatures at the highest heating rates being close to the predicted superheat limit. Considering the assumptions employed in the predictions (i.e., bulk properties, spherical bubbles, etc.), the difference between $\mathrm{T}_{\mathrm{SL}}$ and $\mathrm{T}_{\text {nuc }}$ is not surprising. The gap might be closed by employing contact angle corrections to the bubble shape in the classical theory, accounting for the possibility of nanobubbles being present, or considering the bubble nucleation problem from the perspective of molecular dynamic simulations or density functional theory [11,32-34].

\section{Conclusions}

Pulse-heating stress-minimized Pt films resulted in significant superheating of several organic liquids (ethanol, methanol, butanol, and heptane) to near their predicted superheat limits at the highest heating rates and shorted pulse times imposed in the experiments. The results show that the microstructures and methods used here result in sufficient resolution to detect bubble nucleation for a variety of pulse-heated organic liquids at heating rates on the order of $10^{8} \mathrm{~K} / \mathrm{s}$. Such high rates can suppress the influence of solid imperfections and promote a phase transition governed by density fluctuations. Predictions from homogeneous nucleation theory are consistent with nucleation temperatures that correspond to the highest heating rates. Lower nucleation temperatures are not explained exclusively by nucleation theory, as pre-existing nucleation sites may influence the phase transition process.

\section{Acknowledgements}

The authors are pleased to acknowledge the ELI program at Cornell for partial support to EJC, DHC and JR during the course of this investigation. The assistance of Corinne Lippe and Kyle Skyllingstad of Cornell in developing some of the heptane measurements is greatly appreciated. Discussions with Bruce Land of Cornell in the early phases of this work regarding the bridge circuit design were helpful. Fabrication of the nanostructured devices was carried out at the NIST Center for Nanoscale Science and Technology. 


\section{Nomenclature}

A heater surface area $\left(=\mathrm{L}_{1} \times \mathrm{L}_{2}\right.$, figure $\left.3 \mathrm{a}\right)$

Av Avogadro's constant

$\mathrm{c}_{\mathrm{p}} \quad$ specific heat at constant pressure

$\mathrm{h}_{\mathrm{fg}} \quad$ latent heat of vaporization

$\mathrm{J}_{\mathrm{s}} \quad$ nucleation rate (nuclei/ $\left(\mathrm{m}^{2}-\mathrm{s}\right)$

$\mathrm{k}$ thermal conductivity

K Boltzmann constant

$\mathrm{L}_{\mathrm{c}} \quad$ characteristic heater dimension

$\mathrm{m} \quad$ mass per molecule $(=\mathrm{W} / \mathrm{Av})$

$\mathrm{n} \quad$ number of pulse cycles $(=500)$

$\mathrm{P}_{\mathrm{o}} \quad$ pressure surrounding a critical size bubble

$\mathrm{P}_{\mathrm{s}} \quad$ saturation pressure corresponding to $\mathrm{P}_{\mathrm{o}}$

$\mathrm{q}_{\mathrm{B}} \quad$ heat lost to the substrate (figure 1)

$\mathrm{q}_{\mathrm{F}} \quad$ heat transfer to the fluid (figure 1)

$\mathrm{q}_{\text {in }} \quad$ energy input to the metal film $\left(=\mathrm{q}_{\mathrm{B}}+\mathrm{q}_{\mathrm{F}}\right)$

$\mathrm{R} \quad$ gas constant

$\mathrm{R}_{\text {jumper }}$ electrical resistance defined in figure $4 \mathrm{a}$ (i.e., $\mathrm{R}_{2,3}$ or 4 )

$R_{p} \quad$ potentiometer resistance (figure 4a) to balance the bridge

$\mathrm{R}_{\mathrm{ho}} \quad$ electrical resistance of metal film at room temperature

$\mathrm{R}_{\mathrm{h}} \quad$ electrical resistance of metal film during pulsing

$\mathrm{R}_{\mathrm{mp}}$ total measured resistance (including wire connections) during a pulsing operation

$\mathrm{R}_{\text {mpo }}$ total measured (room temperature) resistance including wire connections

$\mathrm{T}_{\mathrm{b}} \quad$ normal boiling temperature at $\mathrm{P}_{\mathrm{o}}$

$\mathrm{T}_{\text {nuc }} \quad$ inflection point temperature

$\mathrm{T}_{\mathrm{o}} \quad$ temperature in the standard atmosphere

$\mathrm{T}_{\mathrm{w}} \quad$ temperature of film surface

$\mathrm{t}$ time

$t^{*} \quad$ nucleation time (figure 2)

$t_{b} \quad$ bubble growth time

$\mathrm{v}$ molar volume

Var variance (eq. A2)

Cov co-variance (eq. A2)

W molecular weight

Greek

$\alpha \quad$ thermal diffusivity $\left(=\mathrm{k} /\left(\rho \mathrm{c}_{\mathrm{p}}\right)\right)$

$\gamma \quad$ thermal effusivity $\left(=\sqrt{\mathrm{k \rho C}_{\mathrm{p}}}\right)$

$\delta \quad$ Pt film thickness

$\rho$ density

$\sigma \quad$ surface tension

$\bar{\sigma} \quad$ standard deviation

$\tau$ pulse time

subscripts

L liquid

v vapor 


\section{References}

[1] Radt B.,, Smith T.A., and Caruso F. Optically addressable nanostructured capsules," Adv. Mater. 16:2184- 2189 (2004).

[2] Yang, J.C., Jackson, G.S., and Avedisian, C.T., Combustion of unsupported methano1/dodecanol mixture droplets at low gravity, Proc. Comb. Inst. 23, 1619-1625 (1990).

[3] Kraemer, T., Printing enters the jet age, Invent Tech. 16, 18-27 (2001).

[4] Asai, A. Bubble dynamics in boiling under high flux pulse heating, J. Heat Transf. 113, 973-979 (1991).

[5] Hong, Y., Ashgriz, N., Andrews, J. Experimental study of bubble dynamics on micro heater induced by pulse heating, 125, 259-271 (2004).

[6] Avedisian, C.T., Osborne, W.S., McLeod, F.D., Curley, C.M. Measuring bubble nucleation temperature on the surface of a rapidly heated thermal ink-jet heater immersed in a pool of water, Proc. R. Soc. Lond. A, vol. 455, pp. 3875-3899 (1999).

[7] Lee, J., Madabhushi, R., Fotache, C., Gopalakrishnan, S., Schmidt, D. Flashing flow of superheated jet fuel, Proc. Comb. Inst. 23, 3215-3222 (2015).

[8] Wood, V., Panzer, M.J., Chen, J., Bradley, M.S., Halpert, J.E., Bawendi, M.G., Bulovic, V. Inkjet-printed quantum dot-polymer composites for full-color ac-driven displays, Adv. Mater. 21, 2151-2155 (2009).

[9] Avedisian, C.T., The homogeneous nucleation limits of liquids, J. Phys. Chem. Ref. Data, 14(3), 695-729 (1985).

[10] Asai, A. Application of the nucleation theory to the design of bubble jet printers, Japanese J. App Phys. 28, 909-915 (1989)

[11] Cavicchi, R.E. and Avedisian, C.T. Bubble nucleation and growth anomaly for a hydrophilic microheater attributed to metastable nanobubbles, Physical Review Letters, 98, 124501 (2007).

[12] Cavicchi, R.E., Avedisian, C.T., Bubble nucleation, growth and surface temperature oscillations on a rapidly heated microscale surface immersed in a bulk subcooled but locally superheated liquid under partial vacuum, Int. J. Heat Mass Transf., 54, pp. 5612-5622 (2011).

[15] Rembe, C., aus der Wiesche, S., Hofer, E.P. Thermal ink jet dynamics: modeling, simulation, and testing, Microelectronics Reliability 40, 525-532 (2000).

[14] Avedisian, C.T., Cavicchi, R.E., Tarlov, M.J., New technique for visualizing microboiling phenomena and its application to water pulse heated by a thin metal film, Rev. Sci. Instrum., 77(6), 063706 (2006).

[15] Ching, E.J., Avedisian, C.T., Carrier, M.J., Cavicchi, R.E., Young, J.R., Land, B.R., "Measurement of the bubble nucleation temperature of water on a pulse-heated thin platinum 
film supported by a membrane using a low-noise bridge circuit," Int. J. Heat Mass Transf., 79, pp. 82-93 (2014).

[16] Cole, R., Schulman, H.L. "Bubble growth rates at high Jakob numbers," Int. J. Heat Mass Transf., 9, 1377-1390 (1966).

[17] V.P. Carey, A.P. Wemhoff, Thermodynamic analysis of near-wall effects on phase stability and homogeneous nucleation during rapid surface heating, Int. J. Heat and Mass Transf. 48, 5431-5445 (2005).

[18] Vargaftik, N. B. Tables on the thermophysical properties of liquids and gases in normal and dissociated states. Washington, DC: Hemisphere (1975).

[19] Kroenlein, K., Muzny, C.D., Kazakov, A.F., Diky, V., Chirico, R.D., Magee, J.W., Abdulagatov, I., Frenkel, M. NIST/TRC Web Thermo Tables (WTT), NIST Standard Reference Subscription Database 3, Professional ed., Version 2-2012-1-Pro; Thermodynamics Research Center (TRC), National Institute of Standards and Technology: Boulder, CO 80305-3337, 2012.

[20] Arutyunyan, G. S., S. S. Bagdasaryan, and A. M. Kerimov. "Experimental study of the isobaric specific heat of n-propyl, n-butyl, and n-amyl alcohols at different temperatures and pressures," Izv. Akad. Nauk Az. SSR, Ser. Fiz. Tekh. Mat. Nauk 6, $94-97$ (1981).

[21] Carrier, M.J. Improvements in microboiling device design, M.S. thesis, Dept. of Materials Science and Engineering, University of Maryland, College Park (2011).

[22] Lundgren, J., SPLINEFIT, (see http://www.mathworks.com/matlabcentral/fileexchange/13812-splinefit)

[23] Skripov, V.P., Metastable Liquids, Halsted Press, John Wiley\&Sons (1974).

[24] Blander, M., Hengsten,.D., Katz, J.L., (1971) Bubble nucleation in pentane, hexane, pentane and hexadecane mixtures, and water, J. Phys. Chem-US, 75(23), pp. 3613-3619 (1971).

[25] Holden, B.S., Katz, J.L., The homogeneous nucleation of bubbles in superheated binary liquid mixtures, AIChE J., 260-267 (1978).

[26] Apfel, R.E. Vapor Cavity Formation in Liquids, Technical Memorandum no. 62, p. 52, Acoustics Research Laboratory, Harvard University, Cambridge, Ma. (1970).

[27] Gomez-Nieto, M., Thodos, G., Generalized treatment for the vapor pressure of polar and hydrogen bonding compounds, The Canadian Journal of Chemical Engineering, Vol. 55, 445-449 (1977).

[28] Gomez-Nieto, M., Thodos, G., A new vapor pressure equation and applications to normal alkanes, Ind. Eng. Chem. Fundamental. vol. 16 (2), 254-259 (1977).

[29] Hakim, D.I., Steinberg, D., Stiel, L.I. Generalized relationship for the surface tension of polar fluids. Ind. Eng. Chem. Fundam. 10, 174-175 (1971). 
[30] Eberhardt, J.G., Kremsner, W., Blander, M. Metastability limits of superheated liquids: bubble nucleation temperatures of hydrocarbons and their mixtures. J. Coll. Interf. Sci., 50, 369-378 (1975).

[31] Reid, R.C., Poling, B.E., Prausnitz, J.M. Properties of gases and liquids. 4th edition, pp. 55-67, McGraw-Hill (1987).

[32] Diemand, J., Angelil, R., Tanaka, K.K., Tanaka, H. Direct simulations of homogeneous bubble nucleation: Agreement with classical nucleation theory and no local hot spots. Phys. Rev. E 90, 052407 (2014).

[33] Maruyama S., Kimura T. Molecular dynamics simulation of a bubble nucleation on solid surface. Heat and Technology 18, 69-73 (2000).

[34] Oxtoby, D.W., Evans, R. Nonclassical nucleation theory for the gas-liquid transition. J. Chem. Phys. 89, 7521-7530 (1988).

[35] Oehlert, G. W. A note on the delta method. American Statistician, 46, 27-29 (1992). 


\section{Figure Captions}

Figure 1: Schematic of metal film microheaters. a) conventional structure with metal film fabricated onto a bulk substrate; b) metal film configuration bonded to a membrane with air on the back side as used in the present study.

Figure 2: Schematic representation of the evolution of average heater surface temperature when a bubble nucleates and grows to cover the surface. $t_{b}$ is the time for a bubble to grow to cover the heated surface. $t^{*}$ is the mean range after initiating the pulse when a bubble grows to cover the surface during the time $t_{b}$.

Figure 3: a) Top view photomicrograph of a Pt metallization with length $L_{1}$ and width $L_{2}$ which is the active area for Joule heating; b) cross-sectional schematic (not to scale) of $\mathrm{Pt}$ film suspended by an SiN membrane; c) photograph of a chip (containing 8 heater arrays ('a' above)) of different aspect ratios glued to a 40-pin dual-in-line package (DIP).

Figure 4: a) Schematic of bridge circuit. The inductance $L$ is variable and $R_{p}$ is adjusted to balance the bridge. b) Top view photograph of component layout (microheater structures of figure $3 \mathrm{a}$ are fabricated on the chip).

Figure 5: Typical calibration curve for $\mathrm{L}_{1}=60 \mu \mathrm{m}$ and $\mathrm{L}_{2}=4 \mu \mathrm{m}$ (figure $3 \mathrm{a}$ ). $\theta$ (eq. 1) is taken from the slope of run 3 after removing lead resistances and then dividing by the room temperature resistance.

Figure 6: Evolutions of temperature for the indicated $V_{\text {in }}$ and $\tau$ for methanol. Tangent lines at the starred points ("*") are shown from which the heating rates in Tables 1-4 are obtained.

Figure 7: Evolutions of temperature for the indicated $V_{\text {in }}$ and $\tau$ for ethanol. Tangent lines at the starred points ("*") are shown from which the heating rates in Tables 1-4 are obtained.

Figure 8: Evolutions of temperature for the indicated $V_{\text {in }}$ and $\tau$ for butanol. Tangent lines at the starred points ("*") are shown from which the heating rates in Tables 1-4 are obtained.

Figure 9: Evolutions of temperature for the indicated $V_{\text {in }}$ and $\tau$ for $n$-heptane. Tangent lines at the starred points ("*") are shown from which the heating rates in Tables 1-4 are obtained.

Figure 10: Variation of reduced nucleation temperatures with heating rates (derivatives at $t^{*}$ in figures 6-9) for (a) methanol, (b) ethanol, (c) butanol, (d) heptane. Lines are included to suggest trends of the data. At the normal boiling points, $\mathrm{T}_{\mathrm{b}} / \mathrm{T}_{\mathrm{c}} \sim 0.68$.

Figure A1 (a) Evolution of $\mathrm{V}_{\text {out }}$ for a $5 \mu \mathrm{s}$ pulse (ethanol) showing time divided into ten equally distributed segments or gates. (b) Schematic of a single gate centered on time $t_{m}$ depicting data which are averaged to determine $\mathrm{V}_{\text {mean }}$.

Figure A2 Measured standard deviations for ten gates (figure A1) from 500 consecutive pulses of water corresponding to three pulse times $(\tau)$. 


\section{Appendix A: Measurement Uncertainty}

An estimate of the uncertainty in the measured temperature of the platinum films, $T(t)$, during a power pulse is discussed in this section. $\mathrm{T}(\mathrm{t})$ is determined by $\mathrm{V}_{\text {in }}, \mathrm{V}_{\text {out }}$, and its relationship with $R_{h}$ as a volumetrically averaged value (over $L_{1} \times L_{2} \times \delta$ in figure 3). This Appendix outlines how the standard deviation, $\bar{\sigma}$, of heater temperature was estimated. The so-called "delta" method [35] is used for this purpose, which approximates the variance of a function of estimators from knowledge of the variances of those estimators.

The output from the digital scope provides $V_{\text {out }}$ is used to obtain $R_{m p}$ (eq. 2), then $R_{h}$ (eq. 3) and finally $\mathrm{T}$ (eq. 1). Eq. A1 uses $\mathrm{V}_{\text {out }}$ data to obtain the standard deviation of $\mathrm{R}_{\mathrm{mp}}$ and eq. A2 converts the standard deviation of $R_{m p}$ to the standard deviation of temperature. The delta method incorporates a Taylor approximation and requires that each random variable be reasonably close to its mean with high probability. The distributions of the estimators should also approach normal distributions. In this study, $R_{m p}$ is a function of the estimators $V_{\text {in }}$ and $\mathrm{V}_{\text {out }}$, as in eq. 2.

From the delta method eq. A1 approximates the variance of $\mathrm{R}_{\mathrm{mp}}$ from the gradient of $\mathrm{R}_{\mathrm{mp}}$ and the covariance matrix between $\mathrm{V}_{\text {in }}$ and $\mathrm{V}_{\text {out }}$, (the "T" superscript denotes transpose). Because $R_{m p}$ is a function of two variables, a vector operation is required. Multiplying the gradient vectors and the covariance matrix results in a scalar value - the variance of $R_{m p}$ - as

$$
\operatorname{Var}\left(\mathrm{R}_{\mathrm{mp}}\right) \approx \frac{1}{\mathrm{n}} \nabla \mathrm{R}_{\mathrm{mp}}^{\mathrm{T}} \operatorname{Cov}\left(\mathrm{V}_{\mathrm{in}}, \mathrm{V}_{\mathrm{out}}\right) \nabla \mathrm{R}_{\mathrm{mp}}
$$

where the number of pulses for each condition (figures 6-9) was $n=500$. From eqs. 1 and 3 we can relate the standard deviations as

$$
\bar{\sigma}\left(R_{\mathrm{mp}}\right)=\bar{\sigma}\left(\mathrm{R}_{\mathrm{h}}\right)=\theta \mathrm{R}_{\mathrm{ho}} \bar{\sigma}(\mathrm{T})
$$

A Matlab program was written to perform the calculations. It should be noted that only the uncertainty associated with voltage data are obtained.. Other uncertainties not 
considered may originate from, for example, the measurement of $\theta$ and the data processing steps used to determine the nucleation temperatures and heating rates.

Standard deviations of temperature were calculated at ten evenly distributed segments, or "gates", of size $\Delta \mathrm{t}$. A schematic is provided in figure A1. A built-in feature of the LeCroy Waverunner 44xi digital oscilloscope used in the experiments (Section 3) allows for computation of the averages of $V_{\text {in }}$ and $V_{\text {out }}$ within each gate. Each average is considered to be one sample out of $n=500$ in calculating the covariance in eq. A1. For each gate, the standard deviation of temperature is then obtained. The number of data points used to obtain averages within a gate was 51,26 , and 6 for pulse widths of $10 \mu \mathrm{s}, 5 \mu \mathrm{s}$, and $1 \mu \mathrm{s}$, respectively, as determined by the sampling rate of the oscilloscope.

To illustrate the results, we used data for water as previously reported [15], though the results are similar for the fluids investigated here. Figure A2 shows the temporal variation of standard deviation computed by the above procedure. It is evident that the standard deviations of the measured temperatures are quite small. 


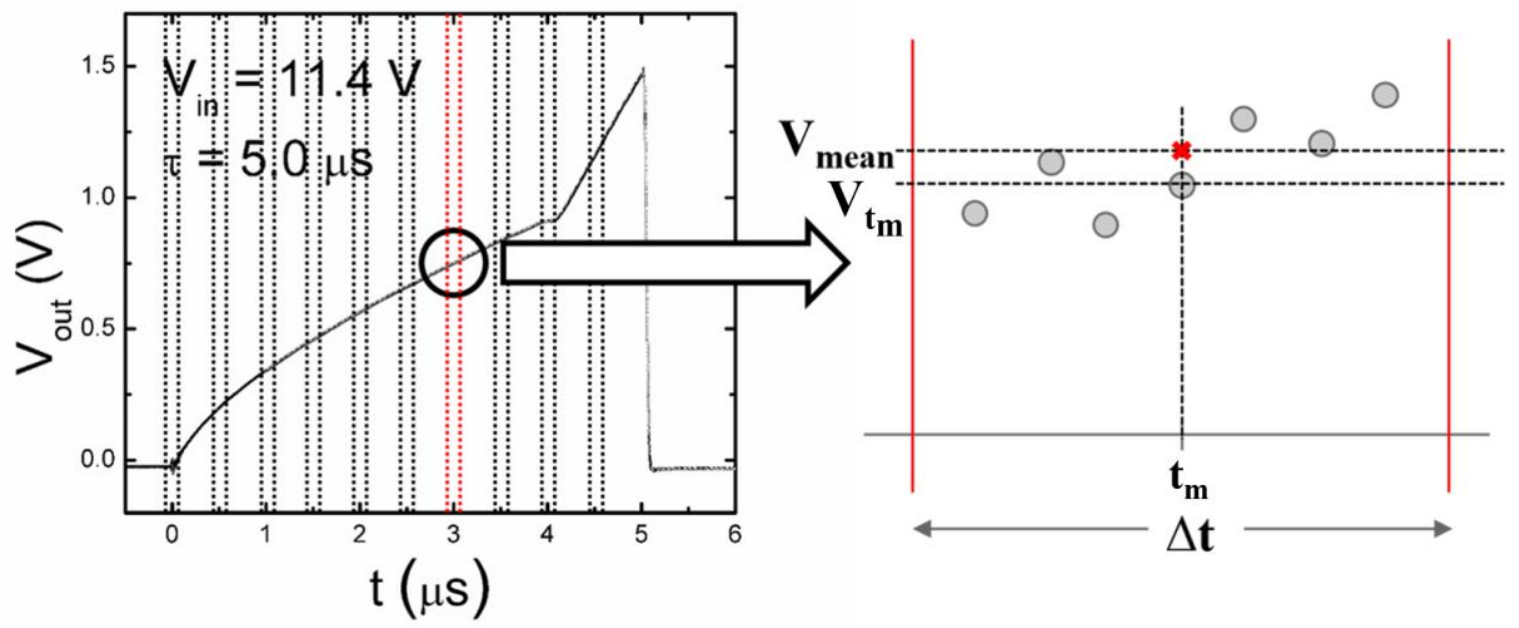

(a)

(b)

Figure A1 (a) Evolution of $\mathrm{V}_{\text {out }}$ for a $5 \mu \mathrm{s}$ pulse (ethanol) showing time divided into ten equally distributed segments or gates. (b) Schematic of a single gate centered on time $t_{m}$ depicting data which are averaged to determine $\mathrm{V}_{\text {mean }}$.

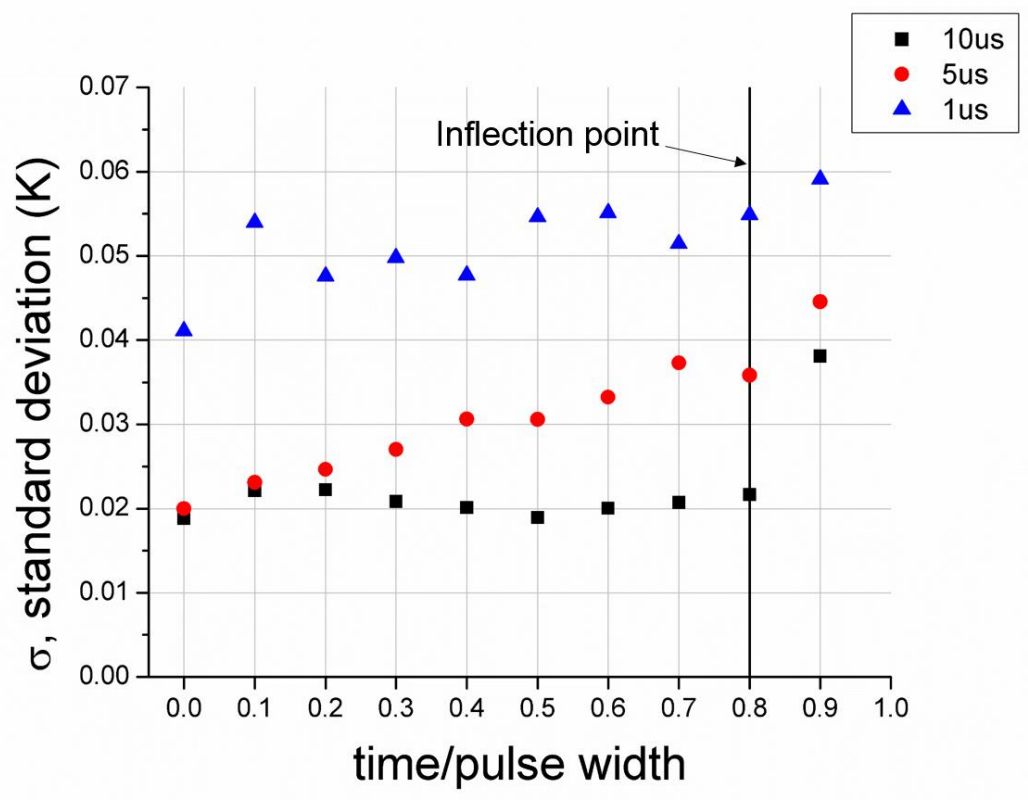

Figure A2 Measured standard deviations for ten gates (figure A1) from 500 consecutive pulses of water corresponding to three pulse times $(\tau)$. 
Table 1 Temperatures, heating rates, and times at the onset of nucleation for methanol $\left(\mathrm{T}_{\mathrm{c}}=512.6 \mathrm{~K}[31]\right)$ over various pulse widths.

\begin{tabular}{|l|l|l|l|l|}
\hline $\mathrm{T}_{\text {nuc }}(\mathrm{K})$ & $\left.\frac{\mathrm{dT}}{\mathrm{dt}}\right|_{\mathrm{t}=t^{*}}(\mathrm{~K} / \mathrm{s})$ & $\mathrm{t}^{*}(\mu \mathrm{s})$ & $\tau(\mu \mathrm{s})$ & $\mathrm{T}_{\mathrm{nuc}} / \mathrm{T}_{\mathrm{c}}$ \\
\hline 427.4 & $1.24 \times 10^{7}$ & 7.78 & 10 & 0.84 \\
\hline 444.0 & $2.87 \times 10^{7}$ & 3.82 & 5 & 0.85 \\
\hline 450.2 & $4.97 \times 10^{7}$ & 2.31 & 3 & 0.88 \\
\hline 456.1 & $1.00 \times 10^{8}$ & 1.40 & 2 & 0.90 \\
\hline 464.9 & $2.06 \times 10^{8}$ & 0.74 & 1 & 0.91 \\
\hline
\end{tabular}

Table 2 Temperatures, heating rates, pulse widths and times at the onset of nucleation for ethanol $\left(\mathrm{T}_{\mathrm{c}}=513.9 \mathrm{~K}[31]\right)$.

\begin{tabular}{|l|l|l|l|l|}
\hline $\mathrm{T}_{\text {nuc }}(\mathrm{K})$ & $\left.\frac{\mathrm{dT}}{\mathrm{dt}}\right|_{\mathrm{t}=\mathrm{t}^{*}}(\mathrm{~K} / \mathrm{s})$ & $\mathrm{t} *(\mu \mathrm{s})$ & $\tau(\mu \mathrm{s})$ & $\mathrm{T}_{\text {nuc }} / \mathrm{T}_{\mathrm{c}}$ \\
\hline 438 & $9.16 \times 10^{6}$ & 7.35 & 10 & 0.85 \\
\hline 448 & $3.07 \times 10^{7}$ & 3.59 & 5 & 0.87 \\
\hline 457 & $5.83 \times 10^{7}$ & 2.17 & 3 & 0.89 \\
\hline 461 & $8.87 \times 10^{7}$ & 1.42 & 2 & 0.90 \\
\hline 467 & $2.12 \times 10^{8}$ & 0.72 & 1 & 0.91 \\
\hline
\end{tabular}


Table 3 Temperatures, heating rates, and times at the onset of nucleation for butanol over various pulse widths $\left(\mathrm{T}_{\mathrm{c}}=563.1[31]\right)$.

\begin{tabular}{|l|l|l|l|l|}
\hline $\mathrm{T}_{\text {nuc }}(\mathrm{K})$ & $\left.\frac{\mathrm{dT}}{\mathrm{dt}}\right|_{\mathrm{t}=\mathrm{t}^{*}}(\mathrm{~K} / \mathrm{s})$ & $\mathrm{t}^{*}(\mu \mathrm{s})$ & $\tau(\mu \mathrm{s})$ & $\mathrm{T}_{\text {nuc }} / \mathrm{T}_{\mathrm{c}}$ \\
\hline 472 & $1.88 \times 10^{7}$ & 7.24 & 10 & 0.84 \\
\hline 481 & $4.07 \times 10^{7}$ & 3.68 & 5 & 0.85 \\
\hline 495 & $7.41 \times 10^{7}$ & 2.22 & 3 & 0.88 \\
\hline 509 & $1.41 \times 10^{8}$ & 1.45 & 2 & 0.90 \\
\hline 514 & $3.03 \times 10^{8}$ & 0.78 & 1 & 0.91 \\
\hline
\end{tabular}

Table 4 Temperatures, heating rates, and times at the onset of nucleation for $n$-heptane over various pulse widths $\left(\mathrm{T}_{\mathrm{c}}=540.3[31]\right)$.

\begin{tabular}{|l|l|l|l|l|}
\hline $\begin{array}{l}\mathrm{T}_{\text {nuc }} \\
(\mathrm{K})\end{array}$ & $\left.\frac{\mathrm{dT}}{\mathrm{dt}}\right|_{\mathrm{t}=\mathrm{t}^{*}}(\mathrm{~K} / \mathrm{s})$ & $\mathrm{t}^{*}(\mu \mathrm{s})$ & $\tau(\mu \mathrm{s})$ & $\mathrm{T}_{\mathrm{nuc}} / \mathrm{T}_{\mathrm{c}}$ \\
\hline 449.4 & $1.30 \times 10^{7}$ & 8.4033 & 10 & 0.83 \\
\hline 462.3 & $2.96 \times 10^{7}$ & 4.1186 & 5 & 0.86 \\
\hline 472.0 & $5.54 \times 10^{7}$ & 2.4971 & 3 & 0.87 \\
\hline 476.6 & $9.44 \times 10^{7}$ & 1.6331 & 2 & 0.88 \\
\hline 484.3 & $2.17 \times 10^{8}$ & 0.72681 & 1 & 0.90 \\
\hline
\end{tabular}


Table 5 Representative property values [18-20] of the fluids investigated, the highest measured nucleation temperatures $\left(\mathrm{T}_{\mathrm{nuc}}\right)$, and the predicted superheat limits $\left(\mathrm{T}_{\mathrm{SL}}\right)$.

\begin{tabular}{|l|ll|l|l|l|l|l|l|l|}
\hline Fluid & $\mathrm{T}_{\mathrm{b}}(\mathrm{K})$ & $\mathrm{T}_{\mathrm{c}}(\mathrm{K})$ & $\mathrm{C}_{\mathrm{pL}}(\mathrm{kJ} / \mathrm{kg} / \mathrm{K})$ & $\rho_{\mathrm{L}}\left(\mathrm{kg} / \mathrm{m}^{3}\right)$ & $\rho_{\mathrm{v}}\left(\mathrm{kg} / \mathrm{m}^{3}\right)$ & $\mathrm{h}_{\mathrm{fg}}(\mathrm{kJ} / \mathrm{kg})$ & $\mathrm{Ja}$ & $\mathrm{T}_{\mathrm{nuc}}(\mathrm{K})$ & $\mathrm{T}_{\mathrm{SL}}(\mathrm{K})$ \\
\hline methanol & 337.9 & 512.6 & 2.83 & 751 & 1.23 & 1121 & 178 & 465 & 471 \\
\hline ethanol & 351.5 & 513.9 & 3.18 & 736 & 1.65 & 849 & 187 & 467 & 482 \\
\hline n-butanol & 390.7 & 563.1 & 3.17 & 725 & 2.28 & 583 & 194 & 514 & 534 \\
\hline n-heptane & 371.6 & 540.3 & 2.56 & 614 & 3.48 & 318 & 173 & 485 & 495 \\
\hline
\end{tabular}


front side

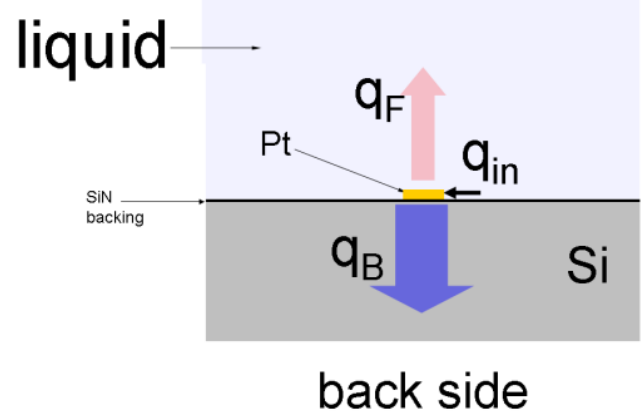

a) front side

liquid

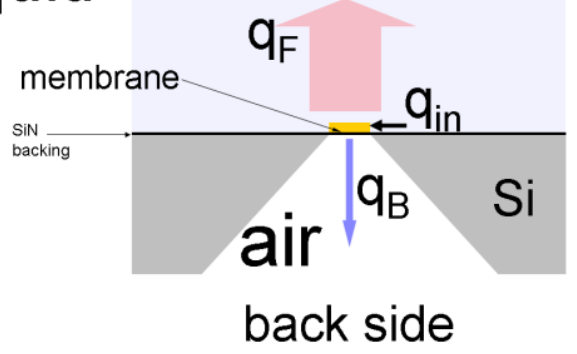

b)

Figure 1: Schematic of metal film microheaters. a) conventional structure with metal film fabricated onto a bulk substrate; b) metal film configuration bonded to a membrane with air on the back side as used in the present study. 


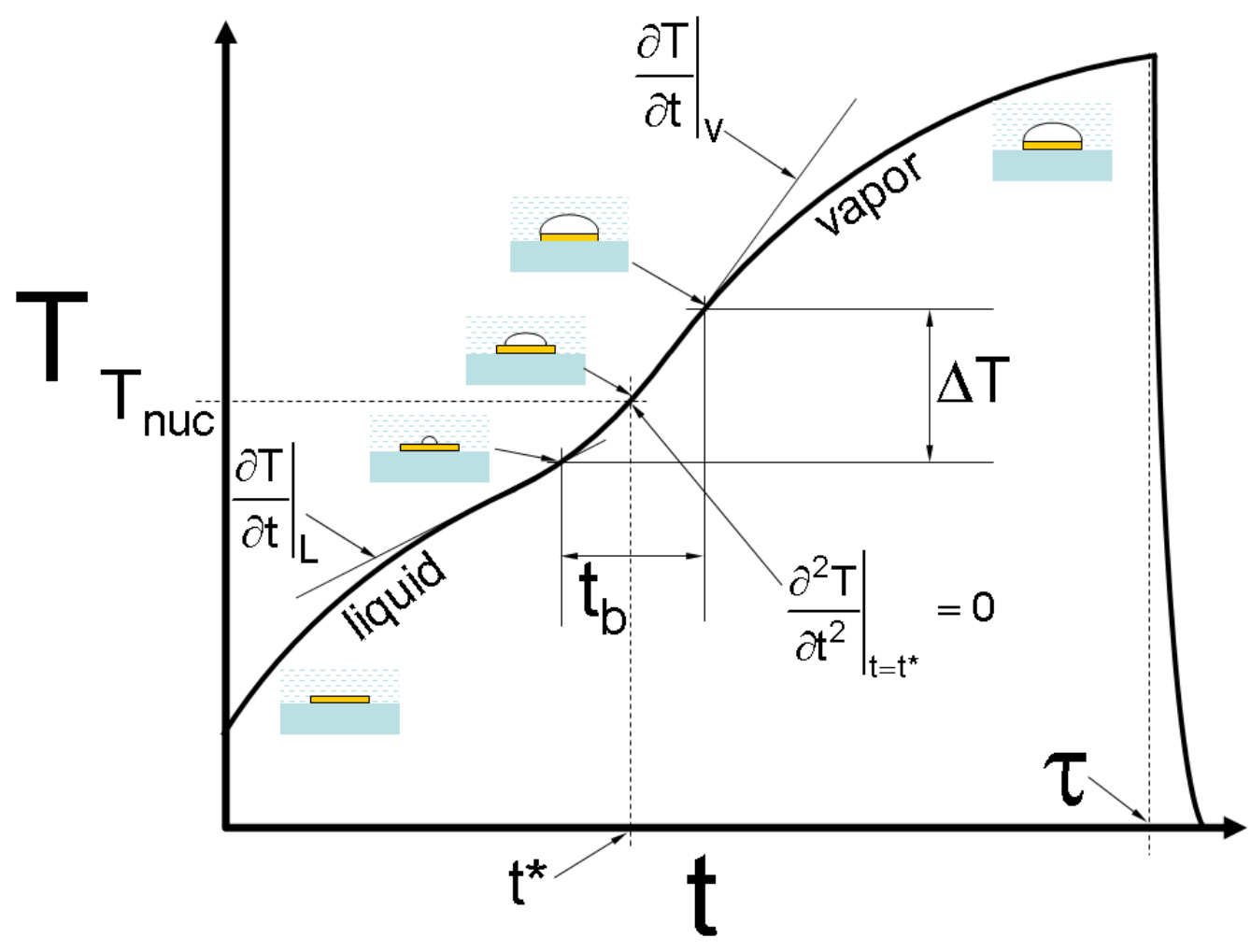

Figure 2: Schematic representation of the evolution of average heater surface temperature when a bubble nucleates and grows to cover the surface. $t_{b}$ is the time for a bubble to grow to cover the heated surface. $t^{*}$ is the mean range after initiating the pulse when a bubble grows to cover the surface during the time $t_{b}$. 


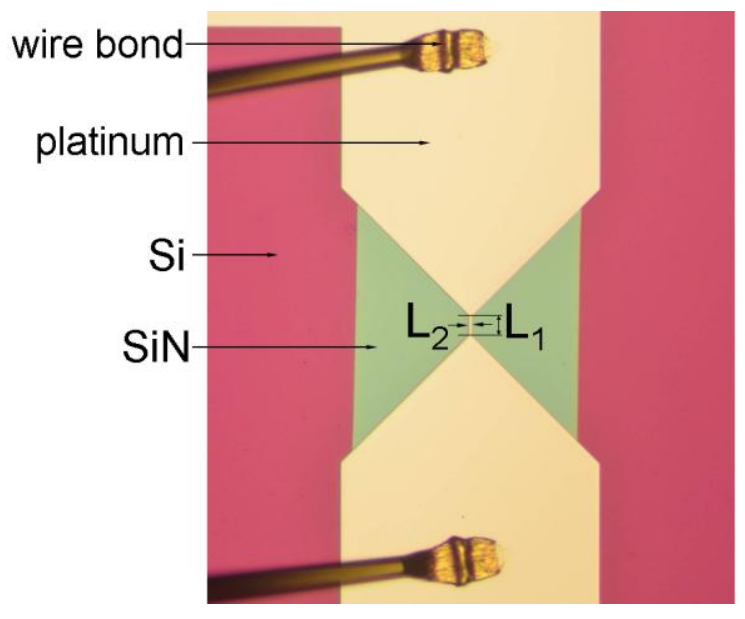

a)

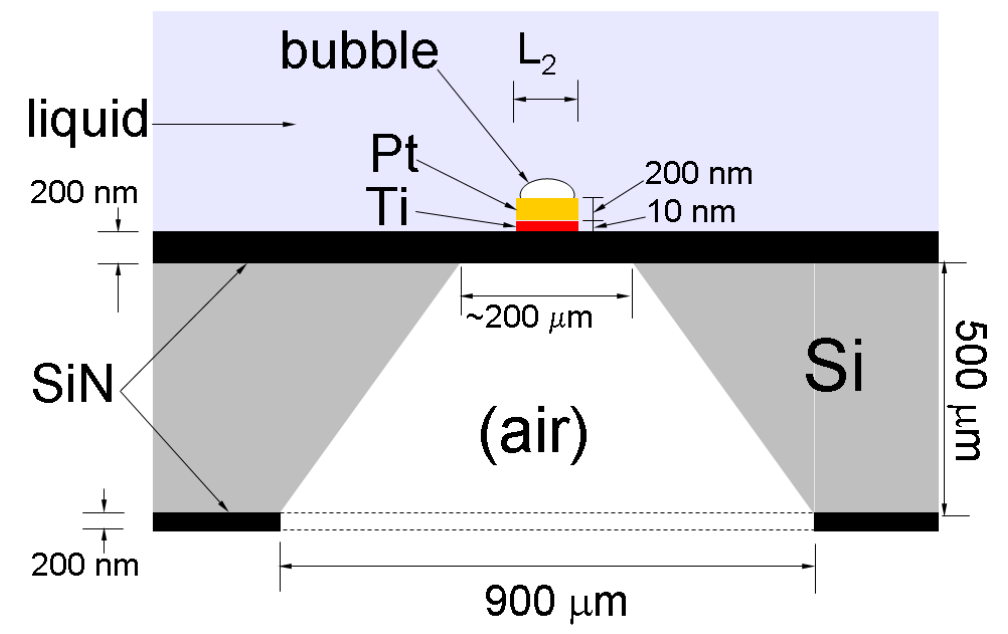

b)

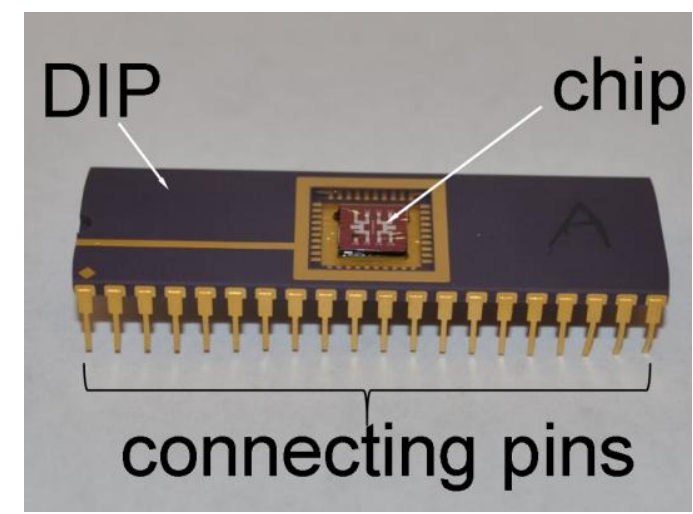

c)

Figure 3: a) Top view photomicrograph of a Pt metallization with length $\mathrm{L}_{1}$ and width $\mathrm{L}_{2}$ which is the active area for Joule heating; b) cross-sectional schematic (not to scale) of $\mathrm{Pt}$ film suspended by an $\mathrm{SiN}$ membrane; c) photograph of a chip (containing 8 heater arrays ('a' above)) of different aspect ratios glued to a 40-pin dual-in-line package (DIP). 


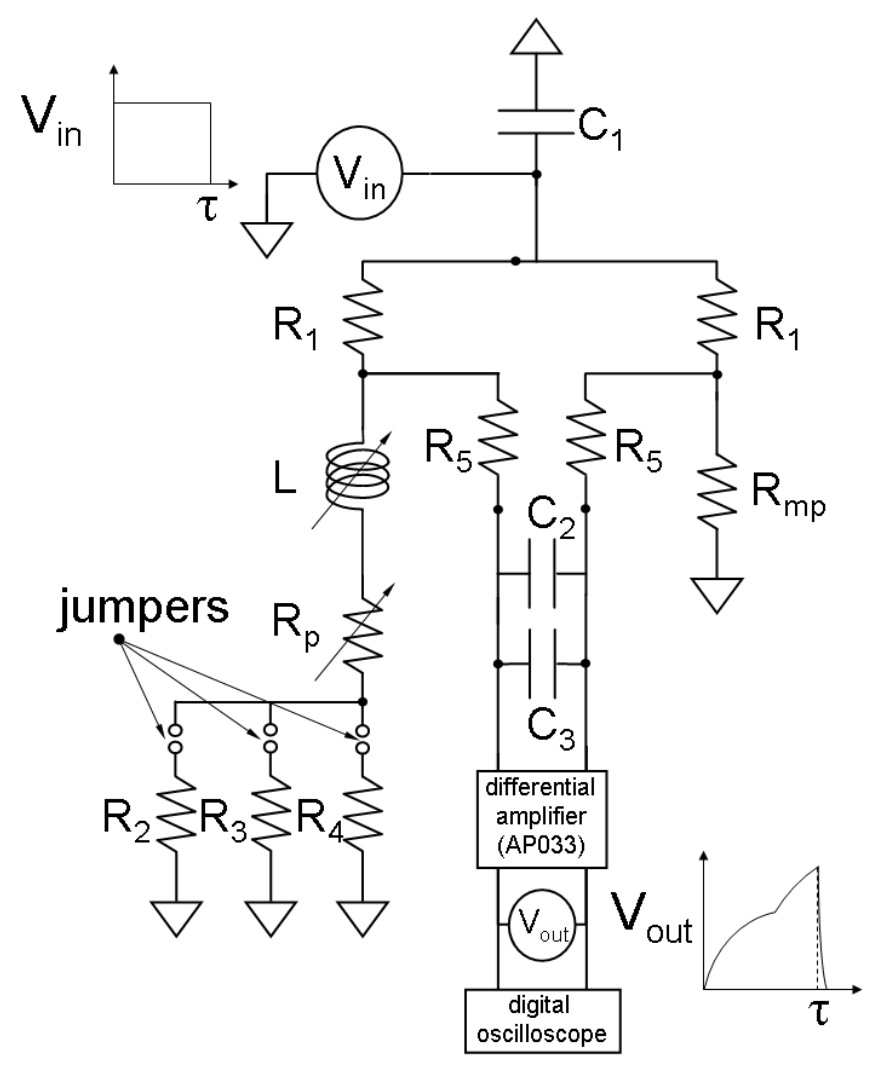

a)

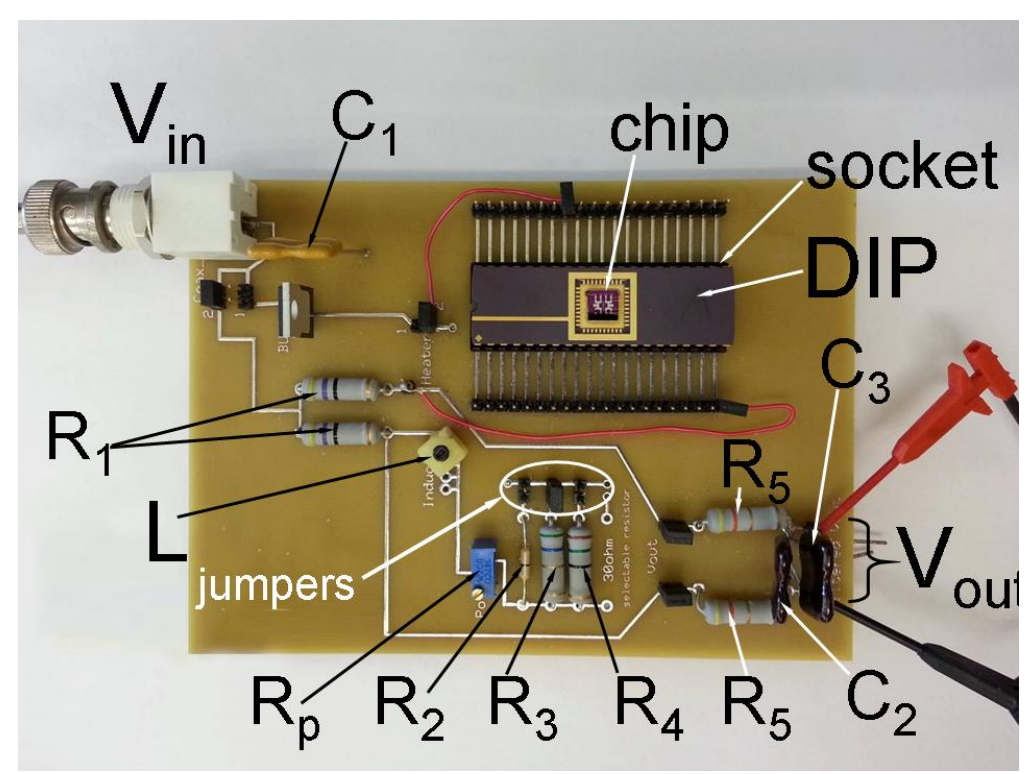

b)

Figure 4: a) Schematic of bridge circuit. The inductance $L$ is variable and $R_{p}$ is adjusted to balance the bridge. b) Top view photograph of component layout (microheater structures of figure $3 \mathrm{a}$ are fabricated on the chip). 


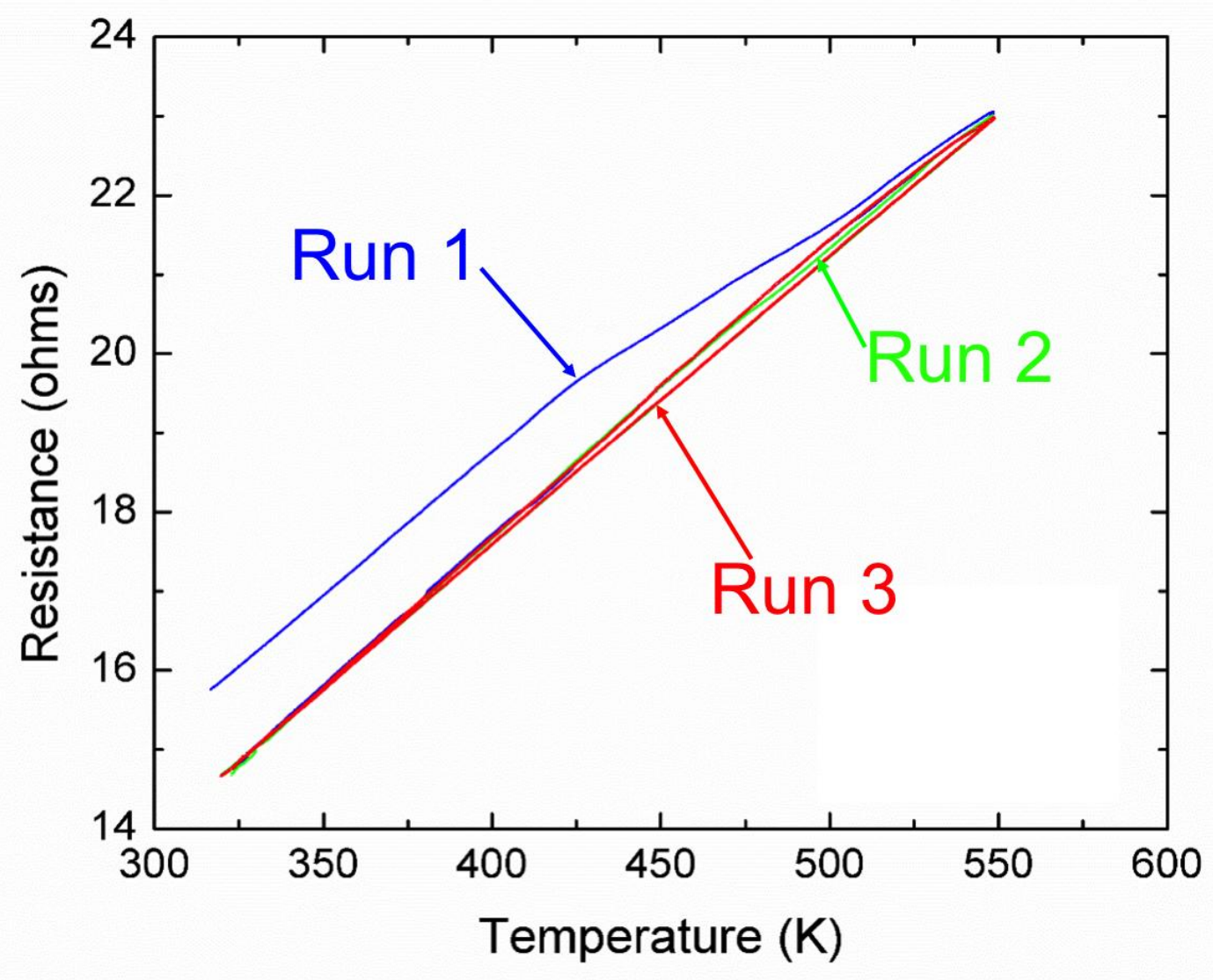

Figure 5: Typical calibration curve for $\mathrm{L}_{1}=60 \mu \mathrm{m}$ and $\mathrm{L}_{2}=4 \mu \mathrm{m}$ (figure $3 \mathrm{a}$ ). $\theta$ (eq. 1) is taken from the slope of run 3 after removing lead resistances and then dividing by the room temperature resistance. 


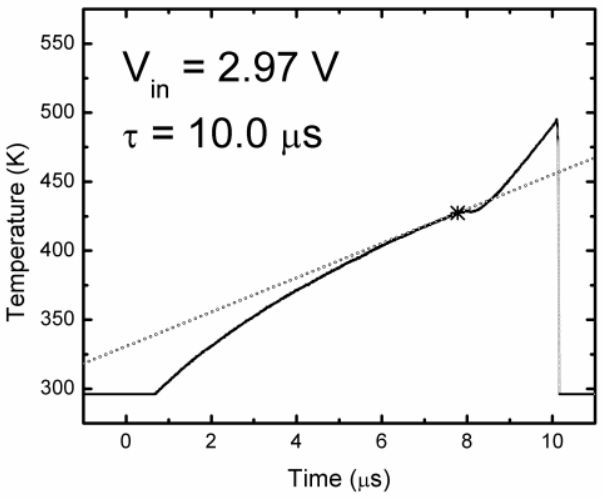

a)

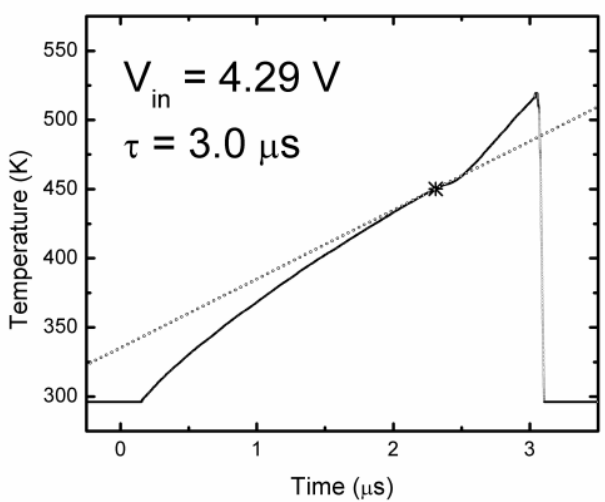

c)

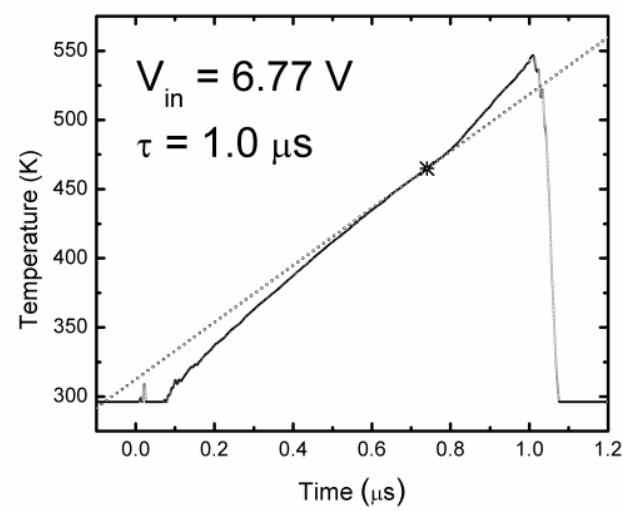

b)
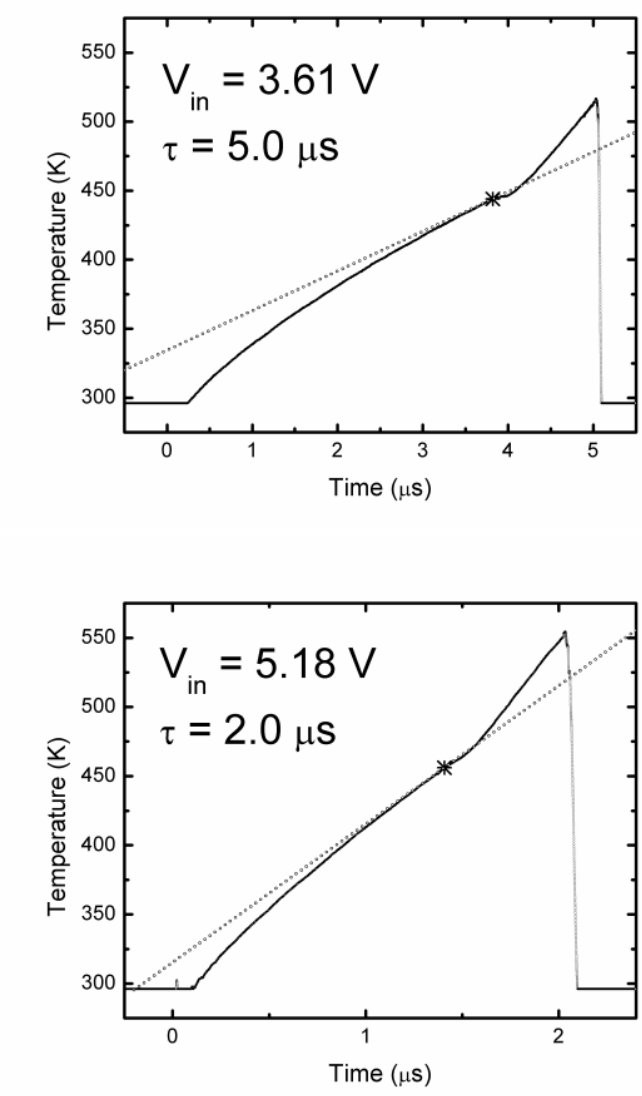

d)

e)

Figure 6: Evolutions of temperature for the indicated $V_{\text {in }}$ and $\tau$ for methanol. Tangent lines at the starred points ("*") are shown from which the heating rates in Tables 1-4 are obtained. 


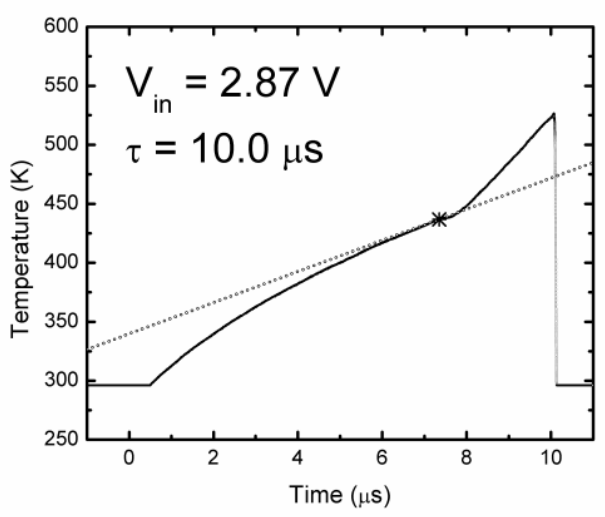

a)

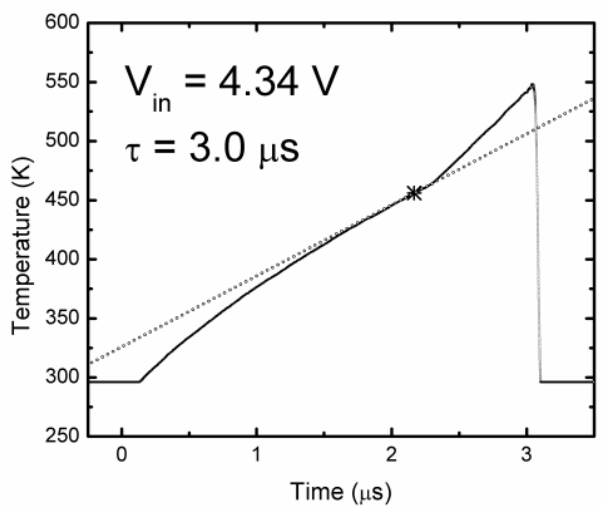

c)

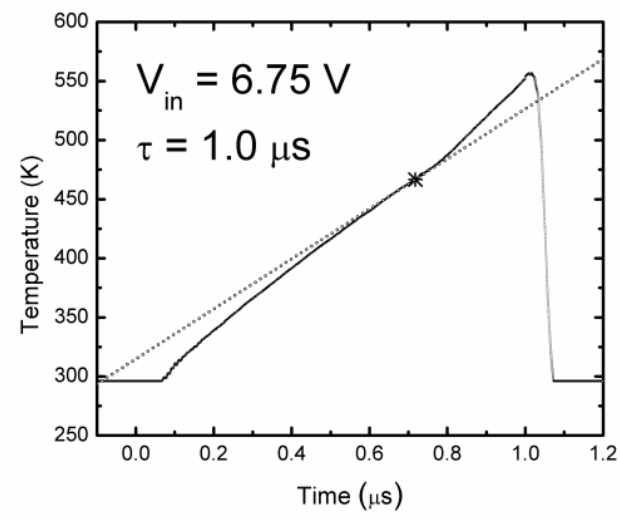

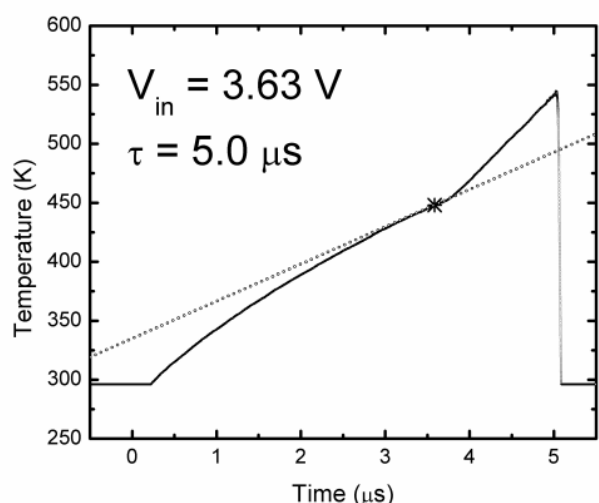

b)

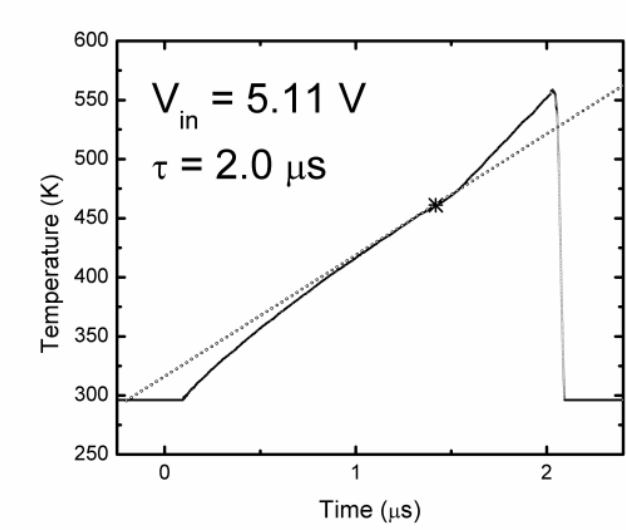

e)

d)

Figure 7: Evolutions of temperature for the indicated $V_{\text {in }}$ and $\tau$ for ethanol. Tangent lines at the starred points ("*") are shown from which the heating rates in Tables 1-4 are obtained. 


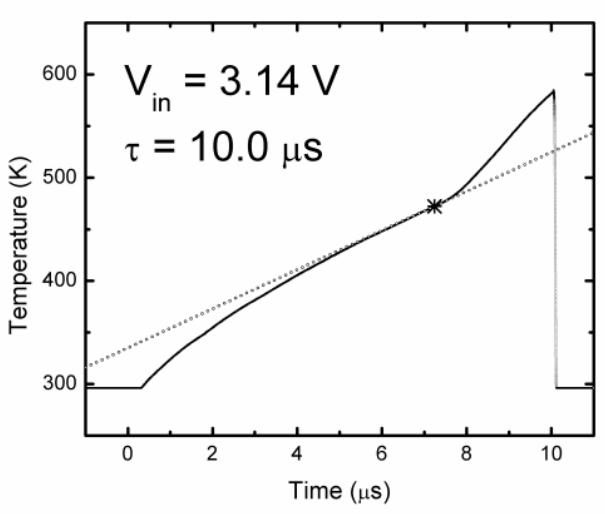

a)

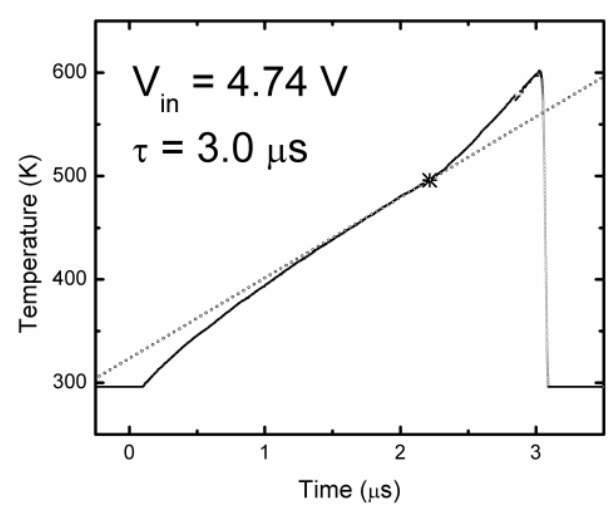

c)

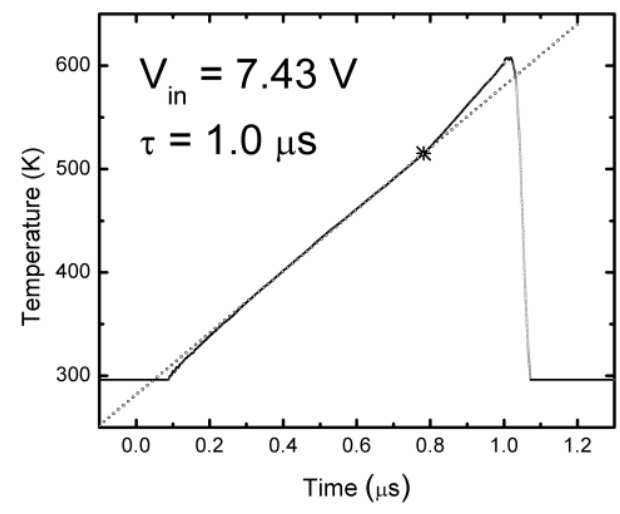

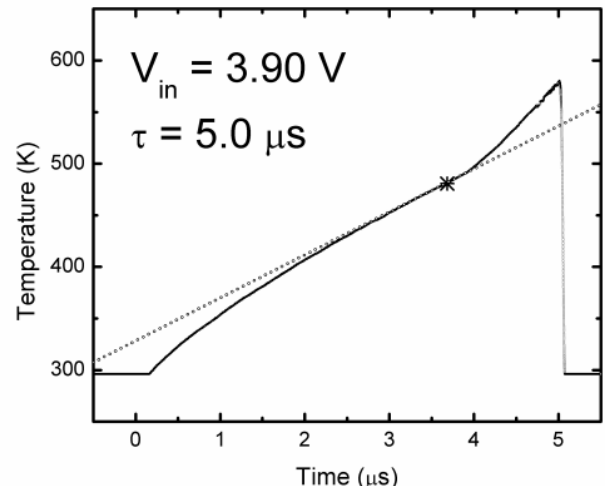

b)

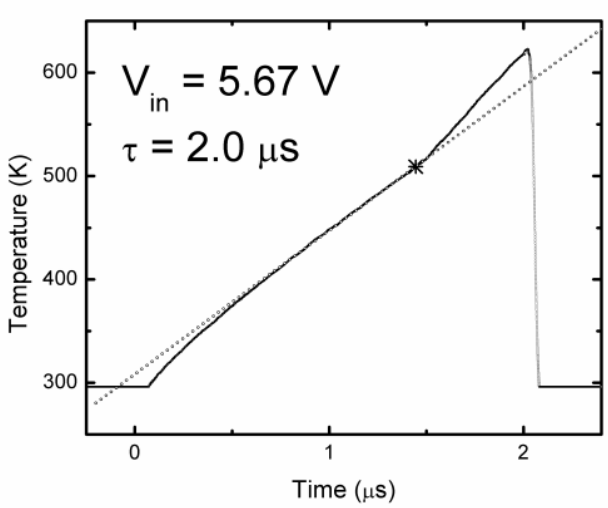

d)

e)

Figure 8: Evolutions of temperature for the indicated $V_{\text {in }}$ and $\tau$ for butanol. Tangent lines at the starred points ("*") are shown from which the heating rates in Tables 1-4 are obtained. 


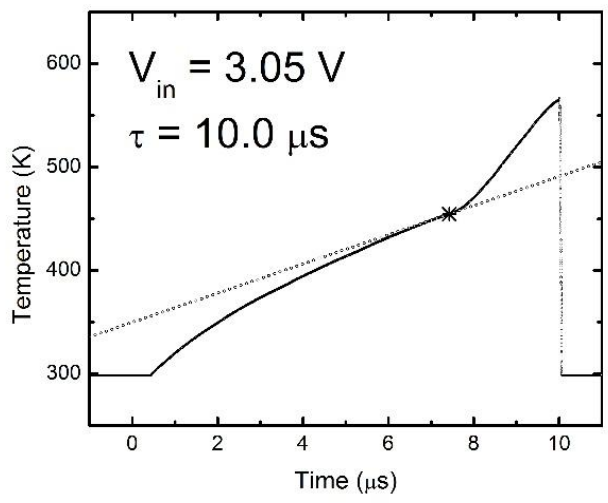

a)

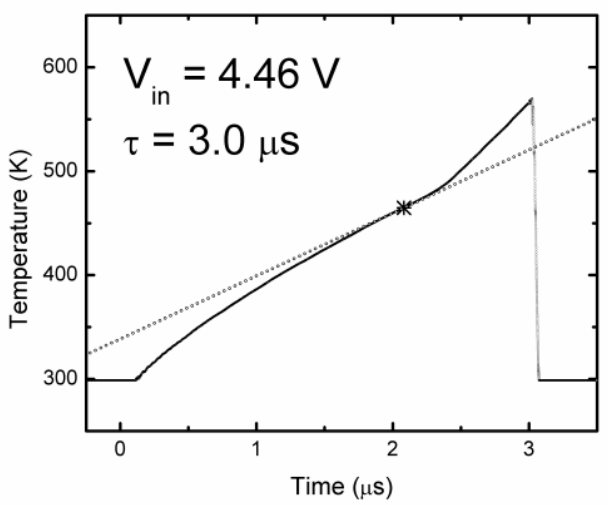

c)

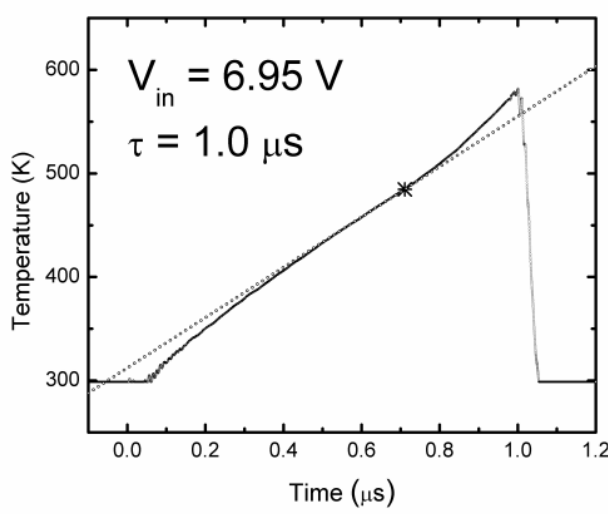

b)
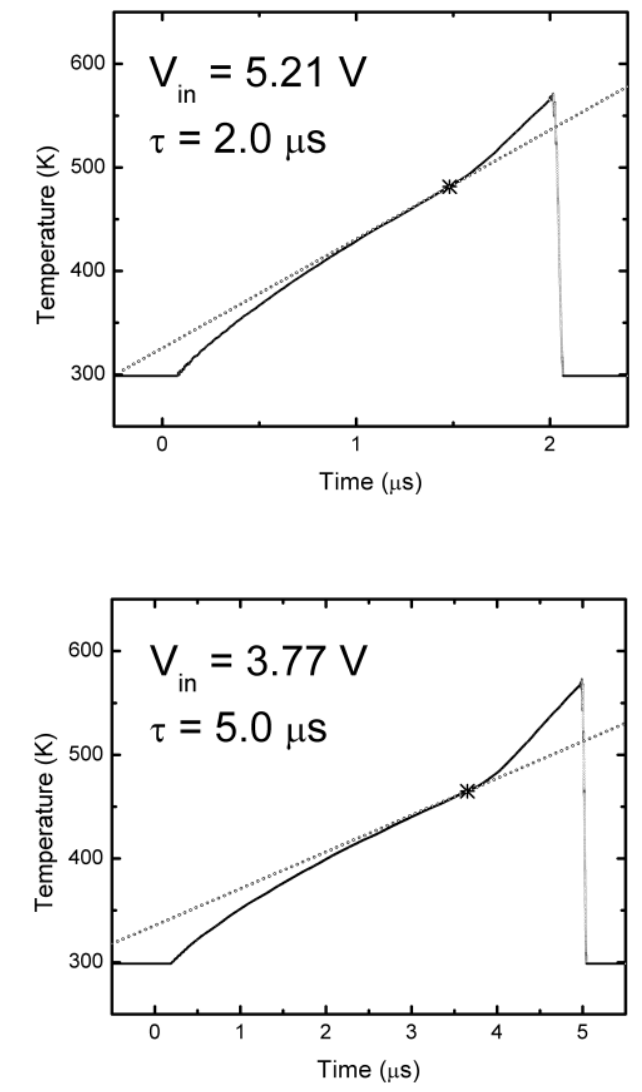

d)

e)

Figure 9: Evolutions of temperature for the indicated $V_{\text {in }}$ and $\tau$ for $n$-heptane. Tangent lines at the starred points ("*") are shown from which the heating rates in Tables 1-4 are obtained. 


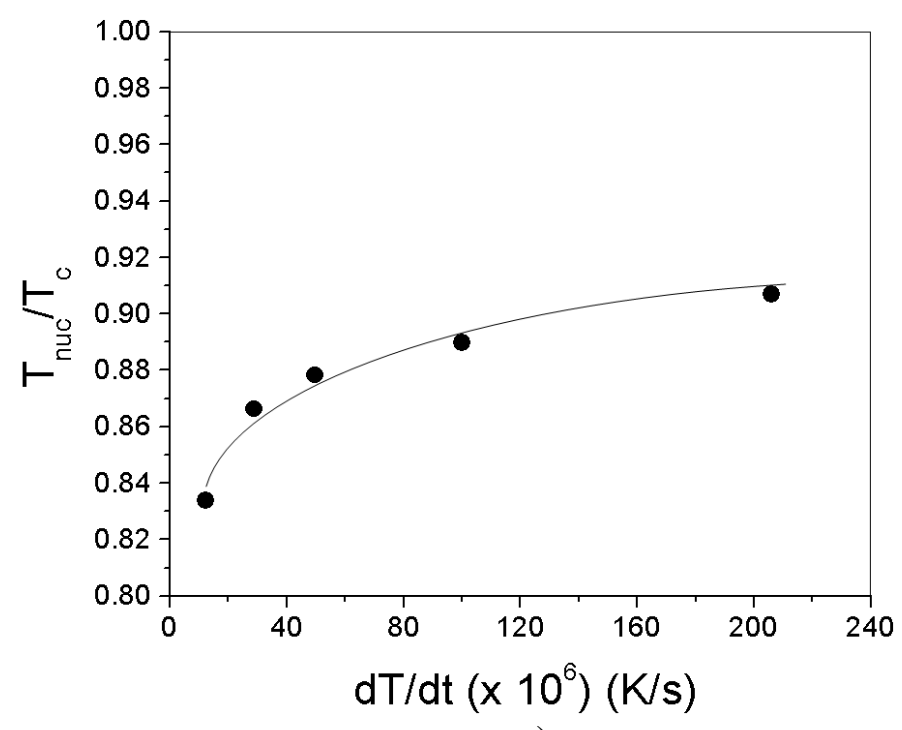

a)

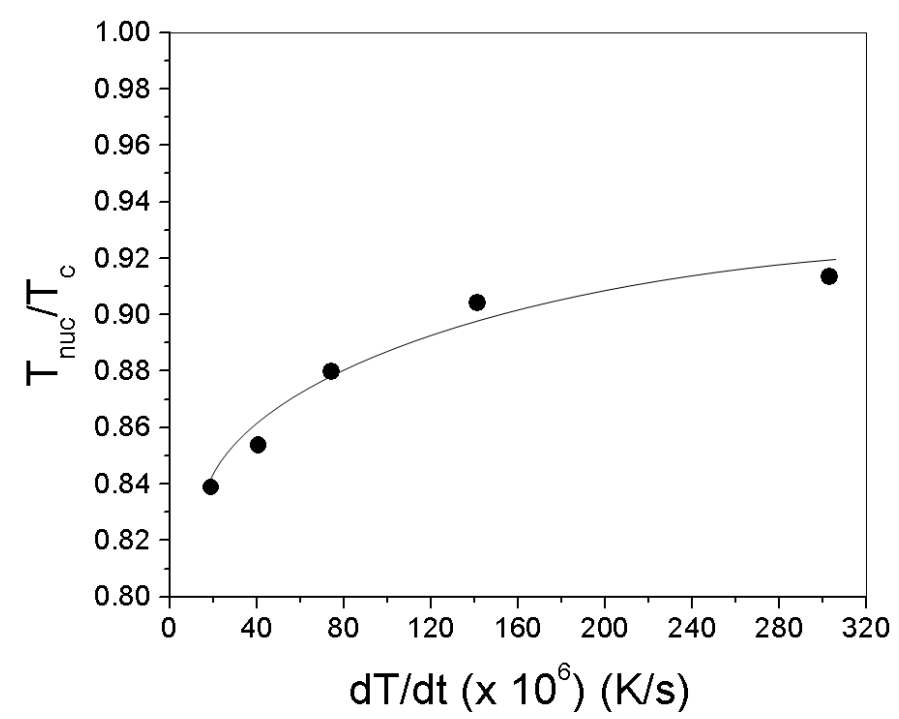

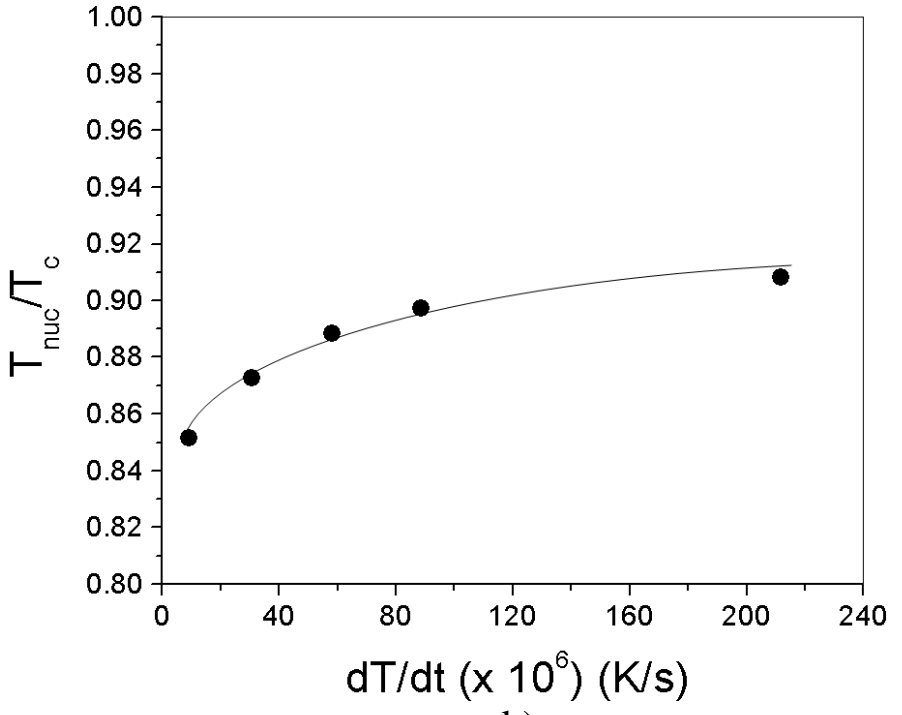

b)

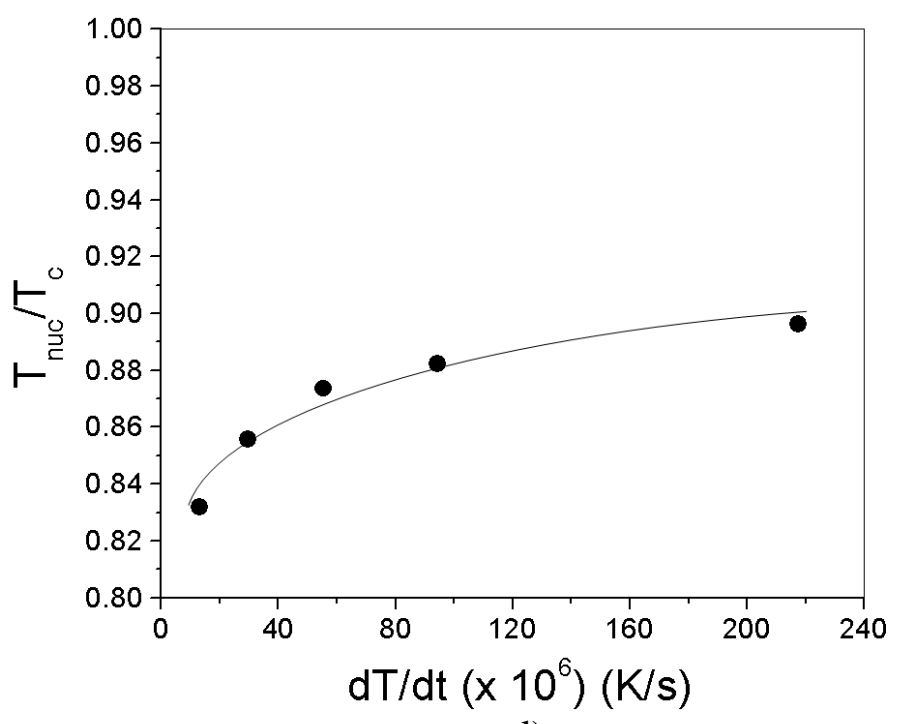

d)

Figure 10: Variation of reduced nucleation temperatures with heating rates (derivatives at $t^{*}$ in figures 6-9) for (a) methanol, (b) ethanol, (c) butanol, (d) heptane. Lines are included to suggest trends of the data. At the normal boiling points, $\mathrm{T}_{\mathrm{b}} / \mathrm{T}_{\mathrm{c}} \sim 0.68$. 